\title{
Concepções sobre Radioatividade Envolvendo Perspectiva Ambiental de Licenciandos de Química
}

\section{Conceptions on Radioactivity Involving the Environmental Perspective of Chemistry Graduates}

\author{
Roberta Maria da Silva ${ }^{a}$; Katia Aparecida da Silva Aquinob; Suely Alves da Silva ${ }^{\mathrm{c}}$ \\ a Secretaria de Educação do Estado de Pernambuco, Universidade Federal Rural de Pernambuco, Recife, Brasil - \\ robertaquimicasilva@gmail.com \\ b Colégio de Aplicação, Universidade Federal de Pernambuco, Recife, Brasil - aquino@ufpe.br \\ c Departamento de Educação, Universidade Federal Rural de Pernambuco, Recife, Brasil - suelyalves@yahoo.com
}

Palavras-chave:

Ensino de ciências.

Mapas conceituais.

Formação de professores.

\section{Keywords:}

Science teaching.

Conceptual maps.

Teacher training.
Resumo: Indo além dos acidentes e cálculos presentes no Ensino de Radioatividade, propomos um novo olhar ao resgatar a condição da radioatividade como fenômeno natural e presente nas nossas vidas mais do que possamos imaginar. Tal noção foi objeto de uma proposta formativa num curso de Licenciatura em Química numa instituição pública de Pernambuco na forma de pesquisa-ação como estratégia. Tivemos como objetivo analisar as concepções dos licenciandos através do uso de mapas conceituais acerca da Radioatividade antes, ao final e três meses após o término da proposta formativa sobre a temática Radioatividade Ambiental. De modo geral, notamos que houve uma gradual evolução especialmente quanto às correções dos equívocos identificados, bem como a consolidação de algumas informações alusivas à perspectiva ambiental. Por meio desses resultados, acreditamos estar contribuindo para o desenvolvimento de novas práticas de ensino com base nos conceitos de radioatividade para futuros professores de química.

Abstract: In the present study we propose a new look at rescuing the condition of radioactivity as a natural and present phenomenon in our lives going beyond the accidents and calculations present in the teaching of radioactivity. This notion was object of a formative proposal in a course of Degree in Chemistry in a public institution of Pernambuco in action research form as strategic. We aimed to analyze the conceptions of licensees about Radioactivity Environmental through the use of conceptual maps produced before, at end and three months after the end of the training proposal. In general, we noticed that there was a gradual evolution of radioactivity concepts, especially regarding corrections of the mistakes identified, as well as the consolidation of some information referring to the environmental perspective. Through these results, we believe in contributing to new teaching practices based on radioactivity concepts of future chemistry teachers. 


\section{Introdução}

Nas escolas ainda é possível encontrar indivíduos que interagem com o conhecimento científico através de informações memorizadas, adquirindo o conhecimento acumulado pelas gerações adultas como verdades absolutas (LUCKESI, 1994). Um ensino desta forma não permite o desenvolvimento de habilidades e competências que levem o estudante a ter uma visão crítica do mundo que o cerca e tal situação é vista como um dos grandes problemas, especialmente no Ensino de Química no Ensino Médio (BRASIL, 2000).

Espera-se então que o Ensino de Química seja um instrumento cultural na educação humana, como meio coparticipante da interpretação do mundo e da ação responsável na realidade em que o estudante está inserido. Ensinar Química no Ensino Médio é possibilitar ao estudante uma compreensão mais abrangente dos processos químicos que estão a sua volta fazendo relação com o conhecimento científico (BRASIL, 2000).

Tendo em vista esse objetivo e de formar um cidadão apto a interpretar e atuar na sociedade, o Ensino de Química precisa estar centrado na inter-relação entre a informação química e o contexto social do indivíduo para que o mesmo possa conviver na sociedade. Nessa ocasião, procura-se voltar às atenções aos conceitos científicos e aspectos tecnológicos e sociais, sem abrir mão da relação com as questões socioambientais (SANTOS; MÓL, 2006).

Nesse sentido, as atividades didáticas precisam estar voltadas para práticas contextualizadas. Segundo Moreira (2017), a contextualização deve ser compreendida como uma necessidade pedagógica para que os conteúdos conceituais ensinados, além de facilitar o processo ensino-aprendizagem, tornem-se relevantes dentro de uma problemática socioambiental.

Nesta direção, é esperado o acesso aos conhecimentos químicos que permitam a "[...] construção de uma visão de mundo mais articulada e menos fragmentada, contribuindo para que o indivíduo se veja como participante de um mundo em constante transformação" (BRASIL, 2000, p. 32). Com isso, há a necessidade de se buscar junto ao Ensino de Química uma prática em que o estudante fale mais e o professor expõe menos (LIBÂNEO, 2013) o que inclui a bagagem conceitual individual e suas interpretações para a construção de novos conhecimentos (AUSUBEL, 2000).

O Ensino de Química nesse contexto não deve ser abordado como se fosse um conhecimento isolado, abstrato e sem aplicação. O estudante deve reconhecer a Química como um corpo de conhecimento capaz de levá-lo a refletir sobre os diversos fenômenos do seu cotidiano e difundidas no mundo numa perspectiva crítica quanto aos seus impactos no campo social, tecnológico, político, econômico e ambiental. Dizemos isso, baseado no que afirma aos Parâmetros Curriculares Nacionais do Ensino Médio (PCNEM) (BRASIL, 2000), que alega ser o Ensino de Química das escolas muito distante do que se pretende. 
Em complementação as Orientações Curriculares para o Ensino Médio (OCEM) (BRASIL, 2006) recomendam que os estudantes compreendam os conteúdos a partir de temas sociais como, por exemplo, o uso da energia nuclear e os perigos envolvidos ante aos fatos históricos em volta da Radioatividade.

Em razão da importância não só política como também socioambiental das atividades antrópicas relacionadas com a Radioatividade, ainda é exercido um sobre este tema centrado em cálculos envolvendo tempo de meia-vida de algum radioisótopo, ou até mesmo balanceamento de equações nucleares por serem os principais elementos explorados pelos livros didáticos (SILVA; SIMÕES NETO, 2012). Cônscios de que a Radioatividade se trata de um fenômeno natural com o qual estamos em constate interação, investimos, de forma quase-experimental, numa proposta de formação em Radioatividade Ambiental (R.Am.) num curso de formação inicial de professores de Química. Com isso, traçamos como objetivo para esta comunicação analisar as concepções dos licenciandos, através da análise de mapas conceituais individuais, acerca do tema Radioatividade antes, ao final e três meses após a aplicação da proposta de formação usando a temática R.Am.

\section{Uma nova proposta para o Ensino de Radioatividade}

Após divulgar a Teoria da Aprendizagem Significativa, num período em que a educação caminhava com as ideias behavioristas, David Ausubel contribuiu para o desenvolvimento da abordagem construtivista cognitivista (MOREIRA; MANSINI, 1982). Originalmente esta teoria foi desenvolvida no âmbito do contexto escolar (JESUS; SILVA, 2004), mas que ganhou o mundo devido sua proximidade com os princípios do construtivismo em ascensão. Em sua Psicologia Educacional, Ausubel afirma que o conhecimento do aprendiz é o fator mais importante no processo de aprendizagem e com base nele o professor deverá direcionar sua prática de ensino (AUSUBEL et al., 1980).

Nesse sentido, Ausubel reafirma um dos princípios construtivistas: a construção do conhecimento como um processo idiossincrático (TAVARES, 2007), isso porque o aprender é uma atividade personalizada. Porém, algumas ações podem torná-las significativas nos momentos de ensino: "[...] que a tarefa de aprendizagem seja potencialmente significativa; e que ele [o estudante] se empenhe psicologicamente de modo ativo na tarefa de modo a relacionar as novas ideias às ideias que já possui na sua estrutura de conhecimento prévia" (MOREIRA et al., 2000, p. 4, acréscimos nossos).

Dessa teoria, dois importantes princípios devem ser levados em consideração quanto à evolução das estruturas cognitivas: a diferenciação progressiva e a reconciliação integrativa (AUSUBEL, 2000). Em termos práticos, esses princípios se aplicam ao planejamento das ações docente quanto à exposição das questões mais gerais para as mais específicas 
(diferenciação progressiva) e o estabelecimento de relações entre os domínios conceituais (reconciliação integrativa).

Na Química, por exemplo, o conteúdo conceitual de Estrutura Atômica é norteador para os estudos da Radioatividade (AQUINO; CHIARO, 2013). O que significa dizer que conhecer previamente o núcleo atômico irá tornar mais fácil de compreender os processos de reação nuclear e as emissões radioativas, abrindo possibilidades para relacionar com os conhecimentos advindos da Física Nuclear e da Biofísica das Radiações.

Fundamentados na Teoria da Aprendizagem Significativa, preocupamo-nos em saber o que futuros professores de Química entendem por Radioatividade, em razão da abordagem desse tema, em geral, restringir-se à cinética das reações nucleares (SILVA; SIMÕES NETO, 2012), ou seja, sem quase nenhuma contextualização ou modificação dos conhecimentos prévios. Jacob e Messeder (2012) e Sá e Santin Filho (2009) alegam que o Ensino da Radioatividade nas escolas é considerado um desafio para alguns professores agravadas quando não se dispõem de acesso a recursos de multimídia, falta de tempo para atualizar-se ou ainda lacunas conceituais na formação inicial deste profissional em relação ao tema.

Diante dessas constatações, vale lembrar que as Orientações Curriculares para o Ensino Médio (OCNEM) (BRASIL, 2006) enfatizam a importância de discutir sobre o uso da energia nuclear e os perigos potencialmente envolvidos, visto que ainda se constata ser pífio o entendimento dos estudantes sobre os impactos sociais da mesma (MESSEDER; PIRES; PIRES, 2013). Situação essa que poderia ser mais bem compreendida mediante a inclusão da abordagem do ciclo natural dos elementos radioativos presentes na água, no solo, no ar e nos alimentos permitindo, assim, dimensionar o fenômeno nuclear no mundo real dando-lhe mais concretude ao objeto de estudo (AQUINO; AQUINO, 2012; AQUINO et al., 2016; OKUNO, 2013). O fato do urânio-238 estar presente na água que bebemos, assim como o carbono-14 presente nos alimentos, são alguns exemplos que permitem levar o estudante romper a barreira entre o estar e o perceber como algo do seu cotidiano (AQUINO; AQUINO, 2012).

$\mathrm{Na}$ atualidade, o mundo vive constantes ameaças vindas da Coreia do Norte de armas nucleares poderosas e com razão, afinal uma arma nuclear possui um potencial destruidor assustador (o Japão que o diga). Além disso, o fenômeno de emissão de partícula e energia de natureza nuclear atômica conhecida como Radioatividade está mais presente no nosso cotidiano do que se pode imaginar.

Este tema está presente em "[...] filmes, livros, desenhos, quadrinho e outras manifestações da cultura moderna. [Isto porque] Sempre é fascinante saber um pouco mais sobre as radiações nucleares e suas aplicações" (SILVA; SIMÕES NETO, 2012, p. 1, acréscimo nosso). Embora isso seja uma realidade, a Radioatividade ainda continua sendo um dos conteúdos de Química do Ensino Médio de menor importância a começar pela sua 
localização e ocupação nos livros didáticos (SÁ; SANTIN FILHO, 2009; SILVA; SIMÕES NETO, 2012; COSTA et al., 2016). Na verdade, este tema habita um terreno interdisciplinar cuja abordagem do ciclo natural dos elementos radioativos ajudaria a explicar a origem do efeito isotópico abordado pela Química.

Outro fator que dificulta o Ensino de Radioatividade nas escolas são as próprias condições de trabalho dos professores que indicam sempre a "[...] falta de interesse, de tempo ou esgotados em sua jornada de trabalho" (SÁ; SANTIN FILHO, 2009, p. 160) como grandes obstáculos para exercer o seu trabalho com maior eficácia. Além disso, o conteúdo conceitual de Radioatividade exige certa sensibilidade por parte de quem for ensiná-la no meio escolar em virtude dos fatos históricos, sobretudo os acidentes nucleares e as bombas atômicas (DOMINGUIN et al., 2012), para que ao final do processo de ensino este fenômeno não seja visto como algo puramente ruim ou maléfico.

E diante desses fatos, as novas tensões políticas reavivam no imaginário da sociedade sobre novos desastres radioativos, ainda que cotidianamente a Radioatividade esteja presente, por exemplo, em exames médicos (COSTA et al., 2016). Em virtude da seriedade que a Radioatividade exige nos últimos tempos, nunca fez tanto sentido a célebre frase atribuída à Marie Curie: "Nada na vida deve ser temido, somente compreendido. Agora é hora de compreender mais para temer menos". Certamente, essa frase exprime bem qual o papel do professor de Química para desconstruir todo esse pessimismo atribuído a Radioatividade, uma vez que a mesma é um fenômeno físico-químico natural em que átomos de núcleos instáveis são capazes de emitir partículas e ondas, cujas propriedades energéticas são de amplo interesse e para diversos fins. Os avanços na Radioatividade artificial viabilizaram o desenvolvimento dos radioisótopos hoje utilizados pela Medicina Nuclear em diferentes diagnósticos e tratamentos, por exemplo. A Radioatividade Artificial pode ser compreendida como o processo de transmutação através de bombardeio de átomos por partículas, sintetizados "[...] em pilhas atômicas, reatores atômicos e aceleradores de partículas" (HENEINE, 1991, p. 39).

Então é de se defender que o objetivo do Ensino de Radioatividade seja focalizado, entre outras coisas, compreender os riscos e benefícios quanto ao uso da energia nuclear em relação às questões sociais, éticas, políticas e ambientais capazes de dialogar com a realidade do estudante (DOMINGUINI et al., 2012; SÁ; SANTIN FILHO, 2009). Este olhar sobre a Radioatividade pode compor um conjunto de informação potencialmente significativa, ou seja, permitir que os conhecimentos prévios dos estudantes sobre Radioatividade (quase sempre obtidos pelos meios de comunicação) possam se modificar, se tornarem mais elaborados e estáveis na estrutura cognitiva dos estudantes (MOREIRA; MANSINI, 1982). 
E antes de prosseguirmos, convém esclarecer os termos Radioatividade Natural, Radioatividade Artificial e Radioatividade Ambiental. A Radioatividade Natural provém do meio ambiente, e "[...] remonta à formação dos átomos, e pode ter milhões de anos. Se existem átomos radioativos naturais, cuja radioatividade dura pouco tempo, é porque se originam de precursores de vida mais longa" (HENEINE, 1991, p. 339). Isto quer dizer que a Radioatividade Natural é decorrente dos radionuclídeos presentes na crosta terrestre (radionuclídeos primordiais) e dos radionuclídeos resultantes das interações dos raios cósmicos (também denominados de radiação cósmica ou galáctica) com a atmosfera (radionuclídeos cosmogênicos) (VASCONCELOS, 2010).

Explicando melhor, desde a origem da Terra a exposição dos seres vivos às fontes naturais de Radioatividade é inevitável. Estando assim o planeta, comumente apto a tolerar certos níveis de Radioatividade, sem maiores consequências. Podemos citar, por exemplo, os raios cósmicos originado do Sol e da Via Láctea, o qual consiste de prótons de alta energia (cerca de 85\%), partículas alfas (cerca de 14\%) e núcleos atômicos mais pesados (cerca de 1\%) (BONOTO, 2004).

Além dessa origem extraterreste, os elementos radioativos também estão presentes na Terra desde seu processo de formação. Exemplo disso são os elementos radioativos Urânio (U) e Tório (Th) presentes nas rochas ígneas (de origem vulcânica). Após sofrerem os processos de intemperismo físico e químico, passam a circular nos diferentes processos biogeoquímicos fazendo presente na água, no ar e solo, e consequentemente na composição química dos seres vivos. Os radionuclídeos naturais por serem originados de fontes naturais estão presentes em diferentes quantidades na natureza, seja nos organismos vivos devido à inalação e ingestão de alimentos e água (exposição interna) como também presente no solo, rochas e minérios, em especial nos materiais de construção (exposição externa) (FERREIRA, 2013).

Portanto, segundo Aquino e Aquino (2012), a exposição do homem às fontes naturais de radiações é inevitável, devido à distribuição de radionuclídeos na crosta terrestre e da intensidade das radiações cósmicas. O Quadro 1 apresenta uma lista de como os diferentes radioisótopos podem ser encontrados na natureza. Diante de tantos radioisótopos naturais que foi possível verificar no Quadro 1, compreendemos que a Radioatividade Ambiental pode ser um caminho possível para ajudar a sanar as dificuldades dos estudantes em tentar compreender o conteúdo conceitual de Radioatividade que, diferente dos enfadonhos cálculos matemáticos, prevê uma forma contextualizada e aplicada deste conteúdo. 
Quadro 1 - Descrições de alguns radioisótopos encontrados na natureza.

\begin{tabular}{|c|c|c|}
\hline GRUPOS & RADIOISÓTOPOS & MANIFESTAÇÕES NA NATUREZA \\
\hline \multirow{4}{*}{ Ametais } & ${ }^{3} \mathrm{H}$ & $\begin{array}{l}\text { O hidrogênio, em geral, não existe naturalmente na forma livre } \\
\text { como um gás, porém encontra-se combinado com outros } \\
\text { elementos como a } \mathrm{H}_{2} \mathrm{O} \text { e } \mathrm{NH}_{3} \text {. }\end{array}$ \\
\hline & ${ }^{14} \mathrm{C}$ & $\begin{array}{l}\mathrm{O} \text { carbono está presente no ar e na água distribuído } \\
\text { uniformemente pela biosfera. Como por exemplo: }{ }^{14} \mathrm{Ce} \mathrm{CO}_{2} .\end{array}$ \\
\hline & ${ }^{32} \mathrm{P}$ & $\begin{array}{l}\text { O fósforo é pouco abundante na natureza, mas em alta } \\
\text { concentração nos tecidos biológicos de plantas e animais de água } \\
\text { doce. }\end{array}$ \\
\hline & ${ }^{131} \mathrm{I}$ & $\begin{array}{l}\text { Presente por todo ecossistema, o iodo entra facilmente nos } \\
\text { sistemas biológicos, sendo utilizado para produção de hormônios } \\
\text { pela glândula tireoide. Também presente nos organismos } \\
\text { dulciaquícolas e marinhos, tais como peixes e algas, considerados } \\
\text { os maiores absorvedores do iodo ambiental. }\end{array}$ \\
\hline \multirow{3}{*}{$\begin{array}{l}\text { Metais } \\
\text { Alcalinos }\end{array}$} & ${ }^{40} \mathrm{~K}$ & $\begin{array}{l}\text { Sua concentração pode aumentar à medida que se aplica potássio } \\
\text { estável no solo através de fertilizantes, e assim ser absorvido } \\
\text { pelas plantas. Dada sua distribuição homogênea e abundância, o } \\
{ }^{40} \mathrm{~K} \text { é responsável por } 14 \% \text { da exposição dos seres vivos à } \\
\text { radiação gama natural. }\end{array}$ \\
\hline & ${ }^{87} \mathrm{Rb}$ & $\begin{array}{l}\text { O rubídio dentro do corpo pode substituir quimicamente o } \\
\text { potássio. É encontrado em alta concentração na rocha granito. }\end{array}$ \\
\hline & ${ }^{137} \mathrm{Cs}$ & $\begin{array}{l}\text { Sua produção é decorrente de resíduos de reatores nucleares. O } \\
\text { césio pode se acumular nas plantas por adsorção foliar, deposição } \\
\text { atmosférica ou "uptake" radicular. Nos animais a irradiação } \\
\text { ocorre por ingestão, inalação e adsorção ou absorção superficial. } \\
\text { Na cadeia alimentar ele é bioacumulativo. }\end{array}$ \\
\hline \multirow{5}{*}{$\begin{array}{l}\text { Metais } \\
\text { Alcalinos } \\
\text { Terrosos }\end{array}$} & ${ }^{7} \mathrm{Be}$ & $\begin{array}{l}\text { O berílio é um Radionuclídeo natural originado das radiações } \\
\text { cosmogênicas pelo processo de espalação de núcleos leves } \\
\text { presentes na atmosfera, tais como carbono, nitrogênio e oxigênio. } \\
\text { A maior parte do berílio é formada na estratosfera. Ele está } \\
\text { associado às partículas de aerossóis as quais se remetem ao óxido } \\
\text { de berílio }(\mathrm{BeO}) \text { e hidróxido de berílio }\left(\mathrm{Be}(\mathrm{OH})_{2}\right) \text {. }\end{array}$ \\
\hline & ${ }^{40} \mathrm{Ca}$ & $\begin{array}{l}\text { O cálcio apesar de ser um elemento abundante na biosfera, a } \\
\text { produção do radioisótopo }{ }^{40} \mathrm{Ca} \text { é insignificante e não chega a ser } \\
\text { um risco radiológico. Podendo ser encontrado em tecidos } \\
\text { biológicos de diversos seres vivos, e em diferentes rochas. }\end{array}$ \\
\hline & ${ }^{90} \mathrm{Sr}$ & $\begin{array}{l}\text { O estrôncio não existe na natureza, pois é proveniente da fissão } \\
\text { do urânio e do plutônio, o qual ocorre nos reatores nucleares e nas } \\
\text { explosões de bombas atômicas. }\end{array}$ \\
\hline & ${ }^{140} \mathrm{Ba}$ & $\begin{array}{l}\text { O bário radioativo é proveniente da fissão nuclear entra na cadeia } \\
\text { alimentar por meio da deposição foliar e inalação. }\end{array}$ \\
\hline & ${ }^{226} \mathrm{Ra},{ }^{228} \mathrm{Ra}$ & $\begin{array}{l}\text { O rádio aparece raramente sozinho na natureza. Ele é formado a } \\
\text { partir do decaimento de urânio e/ou tório. Sendo assim, todos os } \\
\text { minerais e rochas que contêm isótopos naturais de urânio e tório, } \\
\text { consequentemente apresenta quantidades mensuráveis de rádio. }\end{array}$ \\
\hline $\begin{array}{c}\text { Gases } \\
\text { Nobres }\end{array}$ & ${ }^{220} \mathrm{Rn},{ }^{222} \mathrm{Rn}$ & $\begin{array}{l}\text { O radônio é um gás inerte de maior número atômico. Na natureza } \\
\text { esse gás é liberado de rochas e se difunde pelas fraturas, sendo } \\
\text { transportado pela água e pelo ar. }\end{array}$ \\
\hline
\end{tabular}


Quadro 1 - Descrições de alguns radioisótopos encontrados na natureza (continuação).

\begin{tabular}{|c|c|c|}
\hline GRUPOS & RADIOISÓTOPOS & MANIFESTAÇÕES NA NATUREZA \\
\hline \multirow{7}{*}{$\begin{array}{l}\text { Metais } \\
\text { Pesados }\end{array}$} & ${ }^{51} \mathrm{Cr}$ & $\begin{array}{l}\text { O cromo não é considerado um elemento essencial na fisiologia } \\
\text { dos organismos vivos. Ele é muito usado como um traçador } \\
\text { científico. }\end{array}$ \\
\hline & ${ }^{54} \mathrm{Mn}$ & $\begin{array}{l}\text { O manganês está presente na crosta terrestre, não é encontrado na } \\
\text { sua forma pura, contudo faz parte da composição de mais de cem } \\
\text { minérios. Como, por exemplo, a pirolusita }\left(\mathrm{MnO}_{2}\right) \text {, a rodocrosita } \\
\left(\mathrm{MnO}_{3}\right) \text { e a braunita }\left(\mathrm{Mn}^{2+}\left(\mathrm{Mn}^{3+}\right)_{6} \mathrm{SiO}_{12}\right) .\end{array}$ \\
\hline & ${ }^{55} \mathrm{Fe},{ }^{58} \mathrm{Fe}$ & $\begin{array}{l}\text { O ferro é um metal de transição mais abundante da crosta terrestre, } \\
\text { encontrado em meteoritos e em numerosos minerais, tais como a } \\
\text { hematita }\left(\mathrm{Fe}_{2} \mathrm{O}_{3}\right) \text {, a magnetita }\left(\mathrm{Fe}_{3} \mathrm{O}_{4}\right) \text { entre outros. (tabela) }\end{array}$ \\
\hline & ${ }^{60} \mathrm{Co}$ & $\begin{array}{l}\text { O cobalto não é encontrado em seu estado natural, mas combinado } \\
\text { em diversos minerais, sendo considerado um elemento traço no } \\
\text { meio ambiente. }\end{array}$ \\
\hline & ${ }^{65} \mathrm{Zn}$ & $\begin{array}{l}\text { O zinco está presente em baixa concentração na biosfera é } \\
\text { considerado um elemento essencial para o crescimento e utilizado } \\
\text { como um traçador em estudos biológico. }\end{array}$ \\
\hline & ${ }^{210} \mathrm{~Pb}$ & $\begin{array}{l}\text { Embora o elemento chumbo esteja presente em toda a biosfera, o } \\
\text { seu radioisótopo Pb- } 210 \text { é oriundo da atmosfera e litosfera pelo } \\
\text { decaimento do radônio, Rn- } 222 \text {. No ambiente, o elemento se } \\
\text { desloca pelo ar podendo ser inalado. }\end{array}$ \\
\hline & ${ }^{210} \mathrm{Po}$ & $\begin{array}{l}\text { O polônio é naturalmente radioativo. É um elemento raro na } \\
\text { natureza presente em minérios de urânios e pedras de granitos das } \\
\text { profundezas da Terra. }\end{array}$ \\
\hline \multirow[t]{2}{*}{ Actinídeos } & ${ }^{234} \mathbf{U},{ }^{235} \mathbf{U},{ }^{238} \mathbf{U}$ & $\begin{array}{l}\text { O urânio é o elemento que normalmente se acumula nos solos e } \\
\text { sedimentos, e expõe os seres vivos a radiação natural por } \\
\text { processos geológicos, por exemplo, erosão e, poucas vezes, } \\
\text { lixiviação. Ele encontra-se no estado sólido a temperatura } \\
\text { ambiente. }\end{array}$ \\
\hline & ${ }^{232} \mathrm{Th}$ & $\begin{array}{l}\text { O tório é formado pelo bombardeamento do urânio com nêutrons. } \\
\text { E encontrado em quantidades pequenas na maioria das rochas e } \\
\text { solos. }\end{array}$ \\
\hline
\end{tabular}

Fonte: Baseado em Baseado em Aquino e Aquino (2012) e Mazzilli et al. (2011).

As discussões sobre Radioatividade Ambiental podem contribuir para um posicionamento mais crítico dos estudantes na perspectiva de que fenômenos radioativos devem ser temidos quando maus administrados tanto para fins econômicos como por desentendimentos diplomáticos, pois:

O homem e seu meio ambiente sempre estiveram sujeitos à radiação ionizante, sendo continuamente expostos à radiação proveniente do espaço (radiação cósmica), dos radionuclídeos presentes no solo (radiação terrestre ou radionuclídeos primordiais) ou em alimentos, água e ar por ele consumido.

A liberação de materiais radioativos, decorrente de atividades antropogênicas, como utilização de reatores nucleares e testes de explosões nucleares, pode eventualmente contribuir elevando os níveis de radioatividade no meio ambiente e aumentando a dose de radiação dos indivíduos expostos, atingindo valores que podem ser considerados significativos (MAZZILLI et al., 2011, p. 14).

Nesta direção, o estudo dos radionuclídeos naturais e a intensificação dos radionuclídeos cosmogênicos sobre a Terra em razão dos danos à camada de ozônio e entre outras ações, implicaria fazer uma abordagem didática sobre uma cadeia de conceitos que vão 
desde a origem dos elementos radioativos (radiação cósmica e terrestre) e seus ciclos biogeoquímicos, ao menos dos principais elementos (Urânio-U, Tório-Th, Rádio-Ra, Radônio- Rn, e Potássio-K). Além disso, a exploração dos efeitos biológicos da radiação poderá conduzir à discussão em sala de aula sobre os impactos de sua aplicação ao meio ambiente como ao próprio futuro da humanidade. Tais discussões podem ser tornar pontos chaves para a promoção de uma Aprendizagem Significativa.

Cabe salientar que a interferência do homem nos ecossistemas naturais tem proporcionado o aumento da concentração de radionuclídeos devido às suas atividades socioeconômicas gerando, assim, a poluição radioativa decorrentes dos testes nucleares, acidentes, descarte irregular do lixo atômico e da exploração de minérios com fontes radioativas. Desta forma, ao explorarmos a articulação entre a radioatividade natural e artificial na sala de aula estaremos colaborando para desmistificar a ideia de que a Radioatividade é apenas maléfica ou utilizada para fins bélicos com algumas aplicações médicas. Trata-se de um novo olhar sobre algo que desavisadamente negligenciamos por medo de aceitar sua presença no nosso cotidiano.

Neste cenário, acreditamos que quando o licenciando tem a oportunidade de construir os seus conhecimentos de forma significativa é possível que suas práticas pedagógicas caminhem também nesta direção. Por este motivo apresentamos nesta comunicação os resultados obtidos após uma intervenção pedagógica destinada para futuros professores de Química baseada na desmistificação do tema Radioatividade através de discussões sobre a Radioatividade Ambiental.

\section{Metodologia}

A metodologia foi baseada nos pressupostos da pesquisa-ação do tipo estratégica (FRANCO, 2005). Trata-se de uma investigação voltada para obter informações (THIOLLENT, 2005) quanto aos impactos da Radioatividade Ambiental (R.Am.) nas concepções de futuros professores de Química desenvolvida numa perspectiva qualitativa.

Sendo esta uma abordagem voltada para encontrar o sentido do fenômeno em foco à luz da interpretação dos significados dado pelos sujeitos pesquisados (CHIZZOTTI, 2003), o que também não nos impossibilitou de fazer uso de dados quantitativos tendo em vista a presença do paradigma sistêmico nas pesquisas acadêmicas (OLIVEIRA, 2005).

Esta pesquisa introduziu a R.Am. como uma nova proposta de conteúdo conceitual voltado para o Ensino de Radioatividade de forma quase-experimental. As fases da pesquisa, bem como os instrumentos utilizados para análise em cada fase, estão descritas na Figura 1. 


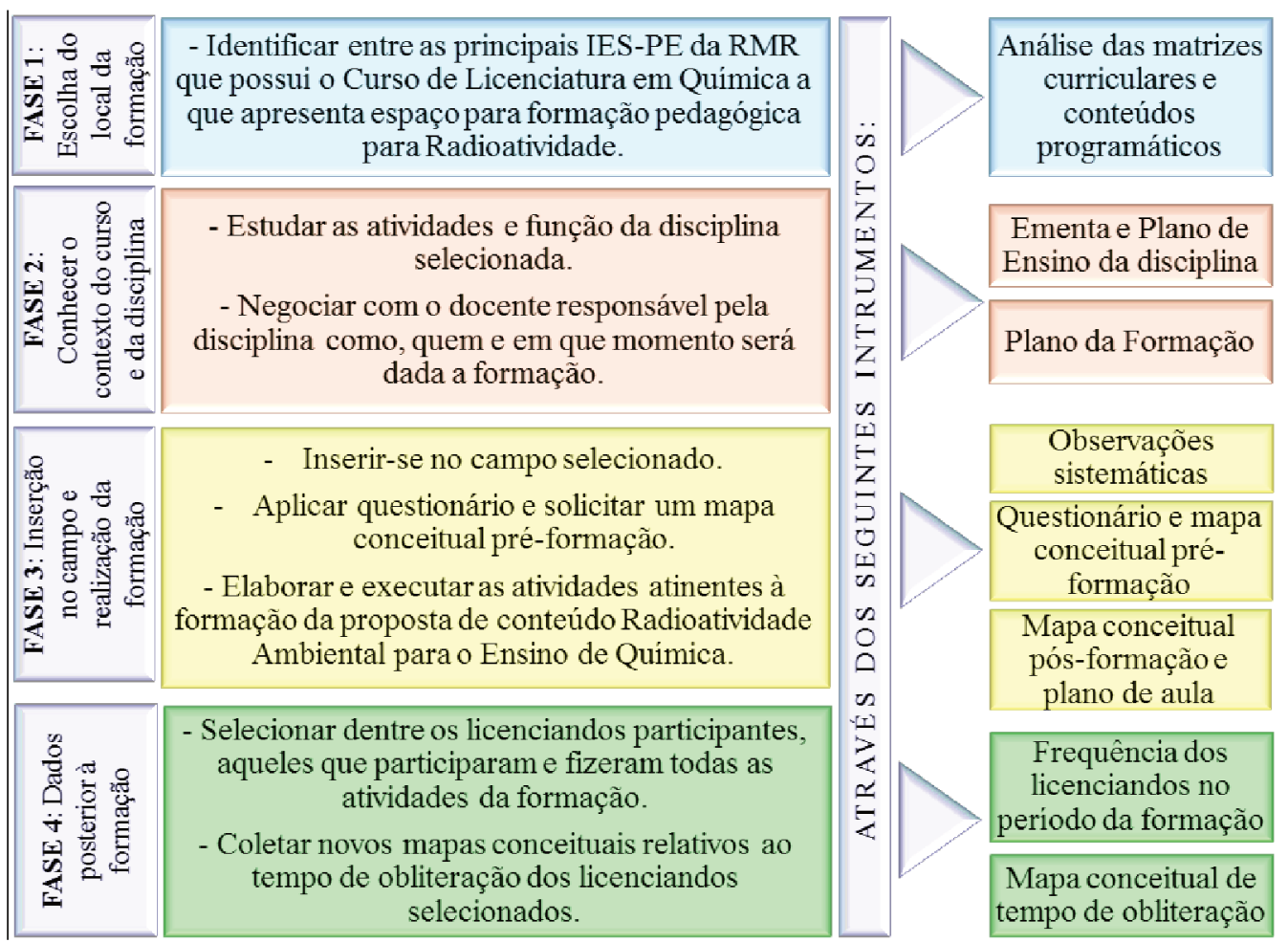

Figura 1 - Fases da pesquisa e os instrumentos utilizados.

Fonte: Autores (2017).

A pesquisa foi realizada no âmbito de uma Instituição do Ensino Superior (IES) pública localizada na Região Metropolitana do Recife (RMR) após termos procedido a uma investigação nas matrizes curriculares e ementas de cursos de Licenciatura em Química das IES do estado de Pernambuco. Como resultado, identificamos existir apenas uma instituição com espaço para formação pedagógica de forma parcial para o Ensino de Radioatividade. Nessa instituição foi escolhido um componente curricular que tem como pré-requisito a aprovação do licenciando num componente curricular de formação científica no primeiro período do curso, cujos tópicos abordados foram relativos a decaimento radioativo, reações nucleares, cinética das radiações, aplicações nucleares e efeitos biológicos (AQUINO et al., 2016).

Através do desenvolvimento das etapas citadas na Figura 1, acreditamos que o período de observação, negociação das atividades sobre R.Am com o docente responsável pelo componente curricular escolhido para a pesquisa, bem como a aplicação do questionário de perfil e a construção do primeiro mapa conceitual individual foram ações suficientes para nos inserirmos no campo da pesquisa (sala de aula) até o momento da formação propriamente dita. Dando-nos segurança, inclusive, para reunir alguns licenciandos três meses depois para última coleta de dados.

As atividades de formação sobre R.Am foram compostas por quatro encontros: IRevisão e discussão dos principais conteúdos conceituais sobre Radioatividade relativos aos tópicos estudados no primeiro período do curso, dificuldades para o Ensino de Radioatividade 
e produção do primeiro mapa conceitual coletivo (Mapa A); II- Apresentação das informações sobre R.Am. (origem e ciclo dos radionuclídeos e impactos socioambientais dos usos de compostos radioativos) e possibilidades de práticas em sala de aula; III- Produção do segundo mapa conceitual coletivo sobre Radioatividade na expectativa que os mesmos espontaneamente introduzissem conceitos relacionados à R.Am. e IV- Produção do segundo mapa conceitual individual (Mapa B) e recolhimento dos planos de aulas - estes últimos não figuram como objetos de análise desta comunicação.

Dos sujeitos participantes, inicialmente havia 21 (vinte e um) licenciandos matriculados, mas para que se configurassem como sujeitos de pesquisa foi necessário selecionar aqueles que participaram de todas as atividades antes e durante a formação sobre R.Am. para, transcorrido um tempo de três meses após a formação (consideramos ser um período de obliteração), solicitamos um novo mapa conceitual individual (Mapa C). Nesse sentido, três sujeitos atenderam ao critério citado, que chamaremos de L1, L2 e L3 para fins de apresentação de resultados.

Quanto ao perfil da amostra, os três sujeitos são alunos regulares do curso de Licenciatura Plena em Química e nunca atuaram como professores profissionalmente. Sublinhamos que todas as atividades foram realizadas mediante concordância dos sujeitos envolvidos (docente e licenciandos) via Termo de Consentimento Livre e Esclarecido.

Como método de análise dos mapas conceituais, partimos do princípio que a proposição é composta por dois ou mais conceitos unidos por frases de ligação que constituem uma unidade semântica ou proposição (NOVAK; GOWIN, 1988), possibilita-nos, desta forma, procedermos à análise de conteúdo de Bardin (1994). Trata-se de uma combinação já experimentada com sucesso, em que foram delimitadas as áreas das proposições acompanhadas de seus respectivos códigos (SILVA et al., 2017). Aqui as proposições serão ilustradas de outra forma onde as unidades de sentido (conceitos) das proposições referentes às diferentes categorias identificadas no mapa conceitual foram preenchidas por cores diferentes. A Figura 2 ilustra as cores códigos que representam cada categoria as quais foram classificados, bem como os demais constituintes dos mapas reconstruídos por meio do software gratuito CmapTools disponibilizado pelo Institute for Human and Machine Cognition (IHMC). 


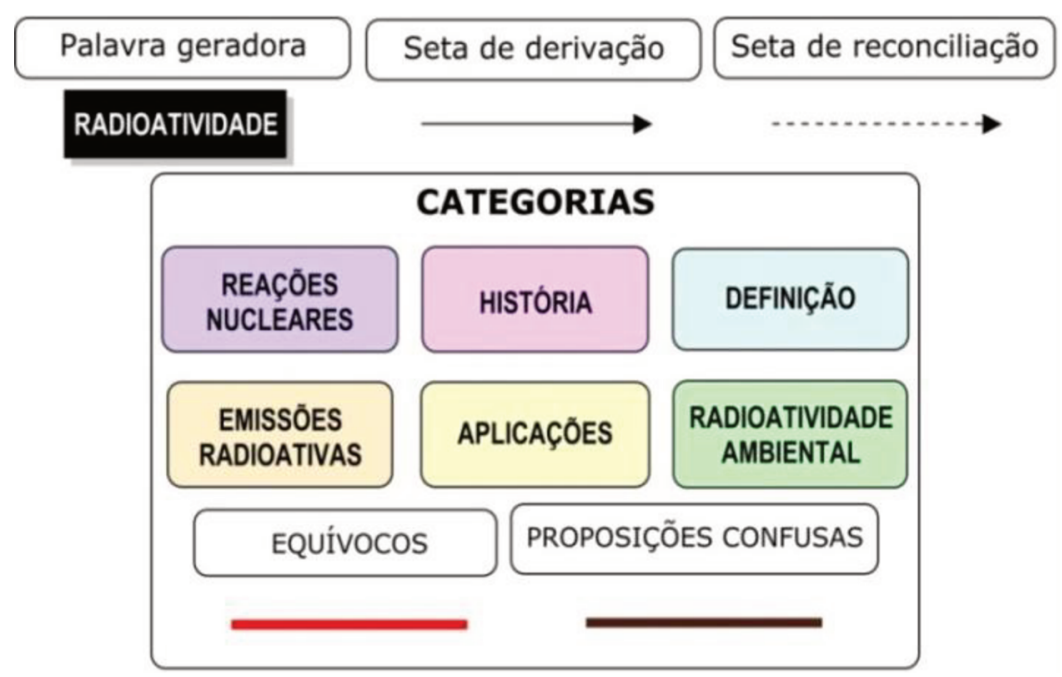

Figura 2 - Constituintes da análise dos mapas conceituais.

Fonte: Autores (2017)

Todos os mapas tiveram como pergunta norteadora: "o que é Radioatividade?", sendo por isso a palavra "Radioatividade" geradora de domínios conceituais e que foram categorizados em:

- "Definição" (Def. - azul), que reúne elementos que de um modo ou de outro representem uma definição de Radioatividade como, por exemplo, uma noção de emissões oriundas do núcleo atômico instável natural ou artificial.

- "História" (His - rosa): relacionado com nomes de personagens e fatos históricos da Radioatividade, como as citações aos acidentes nucleares.

- "Emissões Radioativas" (EmR. - laranja): relaciona conceitos atinentes às radiações alfa, beta e gama.

- "Reações Nucleares" (RNc. - roxo): reúne as informações relativos à fissão, fusão, decaimento e transmutação nuclear.

- "Aplicações" (Apl. - amarelo): trata-se de conceitos relativos as mais diversas aplicações das emissões radioativas.

- "Equívocos" (Equ. - contorno vermelho): áreas identificadas como equívocos conceituais, seja na pertinência da proposição como um todo ou de um conceito específico.

- "Proposições confusas" (PCo. - contorno marrom): regiões onde as proposições estabelecidas são de difícil compreensão, de modo que impossibilita proceder algum tipo de inferência.

A categoria "Radioatividade Ambiental" (RAm. - verde) envolve informações apresentadas durante a formação de mesmo nome, qual seja: radiação cósmica, radiação terrestre, ciclo biogeoquímico dos elementos radioativos, exemplo de alimentos com concentração. Portanto, representa uma nova articulação de informações que dá indícios de 
uma Aprendizagem Significativa em curso. Podendo, inclusive, ser encontrada nos primeiros mapas ao citarem algum nome de elemento químico radioativo naturalmente encontrado no meio ambiente, como menções às radiações cósmicas.

Quantificamos e seguimos a discussão dos sentidos ali presentes tecendo inferências com base nos teóricos apresentados, em busca de indícios, ao compararmos os mapas A, B e C de cada sujeito em diferentes momentos (pré-formação, pós-formação e obliteração). Busca-se encontrar evidências que nos possibilitasse identificar os processos de diferenciação progressiva e/ou reconciliação integrativa na construção dos mapas conceituais.

\section{$O$ contexto da pesquisa}

Antes de prosseguirmos, convém comentar sobre o contexto onde as atividades formativas desta pesquisa se desenrolaram para que a apresentação da análise dos mapas conceituais seja mais compreensível. O componente curricular escolhido para realização desta pesquisa objetivava apresentar, discutir, problematizar e propor estratégias metodológicas para trabalhar conceitos químicos na Educação Básica. Tinha como base princípios epistemológicos e referenciais teóricos específicos que tratam das interações discursivas em sala de aula, dificuldades de aprendizagem e concepções alternativas de estudantes. Ou seja, trata-se de um espaço formativo voltado para o Ensino de Química com base nos conteúdos conceituais estudados previamente pelos licenciandos num componente curricular do primeiro período.

De acordo com o plano de ensino do docente, algumas atividades estavam relacionadas com os pressupostos metodológicos utilizados na formação sobre R.Am. antes mesmo de negociarmos a proposta, os quais tratavam sobre: mapas conceituais; questões sobre o Ensino de Química e Aprendizagem Significativa. E a partir das atividades desenvolvidas pelo docente, acreditamos que os licenciandos teriam construído algum conhecimento prévio pertinente para a elaboração de mapas conceituais antes e durante a formação sobre R.Am.

No primeiro momento da formação realizamos a apresentação da proposta, revisamos e dialogamos sobre algumas das dificuldades relacionadas ao Ensino de Radioatividade. Também resgatamos as concepções prévias sobre dos principais aspectos históricos e conceituais da Radioatividade por meio da produção de um mapa conceitual individual (Mapa A) e da dinâmica da tempestade de ideias. As palavras citadas foram escritas na lousa e está apresentada na Figura 3. 


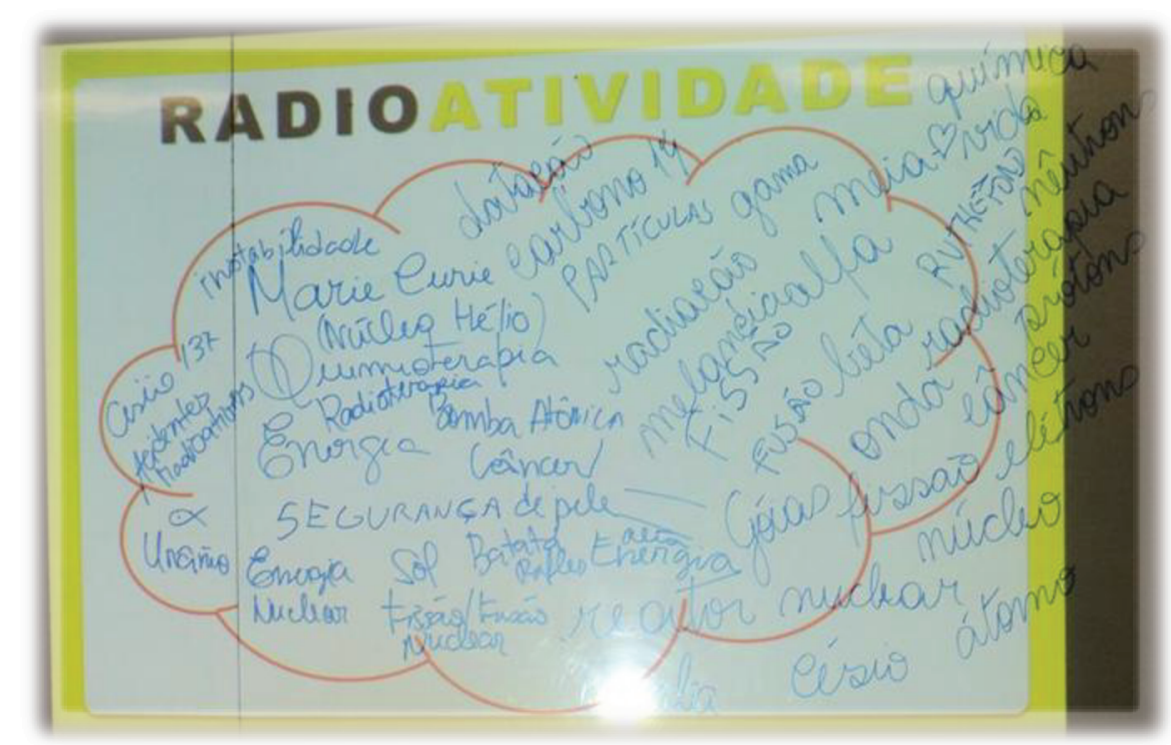

Figura 3 - Imagem da lousa após a dinâmica da tempestade de ideias (conhecimentos prévios dos licenciandos).

Fonte: Artefato da pesquisa (2017).

Tais palavras se apresentaram como reflexos de suas experiências com o tema Radioatividade sejam elas oriundas da formação do primeiro período, de aulas anteriores à formação, na formação na Educação Básica ou por intermédio das notícias veiculadas nos meios de comunicação. Nota-se que as palavras escritas representam imagens sobre a Radioatividade quanto: personagens e fatos históricos, exemplos de elementos radioativos, informações sobre a estrutura atômica, as emissões radioativas, reações nucleares, aplicações nucleares e exemplos sobre efeitos biológicos. Estas palavras foram utilizadas como indicadores de categoria durante o processo de análise dos mapas.

Após esse processo aos licenciandos receberam seus mapas (Mapas A) e produziram mapas conceituais em grupos, conforme sugere Valério (2013), para que trocassem informações entre si. Depois de elaborados, os grupos apresentavam seus mapas coletivos para o grande grupo de forma que novas discussões fossem geradas.

No segundo encontro apresentamos os conceitos que estruturam a ideia da R.Am., bem como diferentes exemplos que poderiam ser explorados na forma de práticas de ensino. Enfatizando a relação entre os radionuclídeos naturalmente existentes e aqueles lançados no meio ambiente pelo homem, além dos que estão constantemente em interação conosco onde quer que estejamos.

O terceiro encontro foi reservado para que os licenciandos, após exposição às informações sobre R.Am., discutissem novamente de forma coletiva e sintetizassem um novo mapa conceitual coletivo. Então voltamos a nos encontrar para solicitar dos licenciandos, além do plano de aula (artificio tanto para a pesquisa, como negociado com o docente para ser incorporado à avaliação), um novo mapa conceitual individual (Mapa B). Vale salientar que todas essas produções foram realizadas em horário de aula a fim de não comprometer o 
processo de sua elaboração - daí o caráter quase-experimental da pesquisa. Por fim, o último mapa conceitual individual (Mapa C) foi coletado na própria IES em contraturno as aulas após passados três meses da intervenção pedagógica em sala, na tentativa de verificar a estabilização cognitiva das informações discutidas na formação sobre R.Am.

\section{Aspectos gerais dos mapas conceituais}

A solicitação de um mapa conceitual antes do processo formativo se deve ao interesse em conhecermos as concepções prévias dos licenciandos sobre Radioatividade, do qual é fruto de suas experiências de vida dentro e fora dos espaços educacionais formais. Ao passo que a elaboração de mapa logo após a sua exposição tende a evidenciar as informações mais significativas apreendidas no momento, mas que verdadeiramente irão se consolidar após um período de afastamento.

Essa última fase é o que caracteriza a assimilação obliteradora, a qual é entendida como uma fase subsequente à Aprendizagem Significativa tenha sido ela ocorrida por recepção ou descoberta. Isto porque o fator “[...] esquecimento é, portanto, uma continuação temporal do mesmo processo de assimilação que facilita a aprendizagem e a retenção de novas informações" (MOREIRA; MANSINI, 1982, p. 18). E com o passar do tempo estas acabam sendo agregadas, esquecidas, deixando algumas impressões na estrutura básica.

Baseados nesses pressupostos, iniciaremos a análise comparando o desempenho geral dos licenciandos nos três mapas conceituais em termos quantitativos de elementos apresentados, conforme ilustra Figura 4. A partir da pré-análise, em especial, na fase de leitura exaustiva recomendada por Bardin (1994), observamos que os conceitos presentes nos mapas elaborados antes formação (Mapa A) havia um maior número de conceitos referentes à categoria "Emissão Radioativa" (40\%), seguida de "Definição" e "Reações Nucleares" (21\% ambas as categorias). E no segundo momento (Mapa B), as categorias citadas acima tiveram algumas reduções percentuais, ao passo de que a "Aplicações" teve um significativo aumento no número de elementos. 


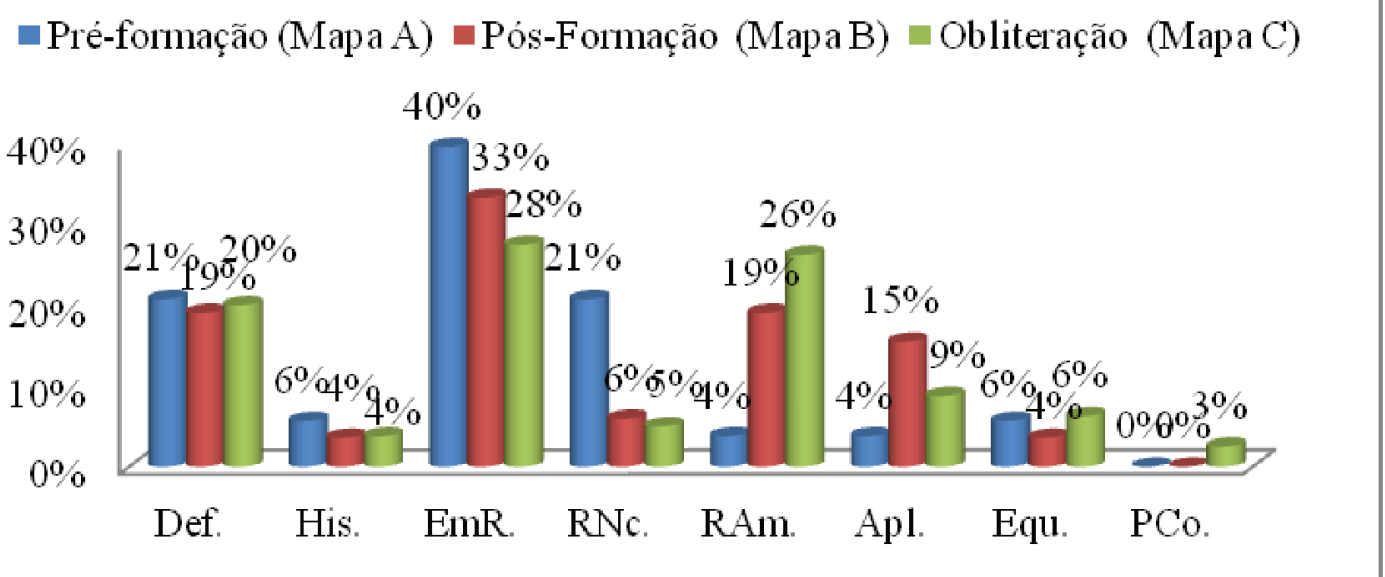

Figura 4 - Distribuição da frequência relativa em diferentes categorias encontradas nos mapas conceituais. Fonte: Autores (2017).

Ainda nesse comparativo, observamos que, no geral, a representação percentual da categoria "Definição" que oscilou, manteve-se praticamente a mesma do primeiro mapa, ainda que a quantidade de conceitos no segundo e terceiro mapa sejam a mesma. Situação similar acontece com a categoria "Equívocos" com relação aos dois primeiros mapas, mas não com a categoria "História" que manteve a mesma representação percentual nos mapas B e no mapa referente ao período de obliteração (Mapa C).

Os elementos identificados quanto às "Emissões Radioativas" e "Reações Nucleares" tiveram reduções graduais, sugerindo que ao analisarmos o conteúdo das proposições dos mapas poderemos constatar mudanças conceituais ou novas articulações dos mapas $\mathrm{A} \rightarrow \mathrm{B}$ por meio de generalizações após a formação em R.Am. (processo de retenção) e/ou mesmo esquecimento (obliteração) de $\mathrm{B} \rightarrow \mathrm{C}$, cujo resultado era esperado devido ao processo de assimilação envolver modificações no subsunçor seja pelo fator tempo como exposição ao novo conhecimento (AUSUBEL, 2000). Sendo esta última uma provável causa para brusca redução de elementos sobre "Aplicações".

Além disso, num dos mapas de obliteração identificamos pela primeiraMoriera

vez uma proposição confusa, que nos impossibilitou compreender a relação ali apontada. Desse cenário, destaca-se a crescente quantidade de informações relativa à "Radioatividade Ambiental" se comparada com as demais categorias que tiveram redução ou estagnaram.

Diante disso, podemos inferir que as informações apresentadas durante a formação além de terem um significativo impacto, também revelam possuírem certa longevidade de retenção, mesmo tento sido observada que uma baixa de quase 5\% na quantidade total de conceitos como se pode notar na Tabela 1, mesmo para L3 que manteve a mesma quantidade de conceitos nos dois últimos mapas. Outra observação que fazemos é que dos três sujeitos L2 e L3 são os que apresentaram uma variedade temática de informações. 
Tabela 1 - Distribuição da quantidade de conceitos segundo as diferentes categorias em todos os mapas: pré (A), pós-formação (B) e de obliteração (C).

\begin{tabular}{|c|c|c|c|c|c|c|c|c|c|c|c|c|}
\hline \multirow{2}{*}{ CATEGORIA } & \multicolumn{3}{|c|}{ L1 } & \multicolumn{3}{|c|}{ L2 } & \multicolumn{3}{|c|}{$\mathbf{L 3}$} & \multicolumn{3}{|c|}{ TOTAL } \\
\hline & $\mathbf{A}$ & $\mathbf{B}$ & $\mathrm{C}$ & $\mathbf{A}$ & $\mathbf{B}$ & $\mathrm{C}$ & $\mathbf{A}$ & $\mathbf{B}$ & $\mathrm{C}$ & $\mathbf{A}$ & B & $\mathrm{C}$ \\
\hline Definição & 3 & 2 & 3 & 6 & 9 & 5 & 2 & 5 & 8 & 11 & 16 & 16 \\
\hline História & 3 & & 1 & & 2 & 1 & & 1 & 1 & 3 & 3 & 3 \\
\hline Emissões Radioativas & 4 & 7 & 4 & 4 & 9 & 4 & 13 & 12 & 14 & 21 & 28 & 22 \\
\hline Reações Nucleares & & 1 & 2 & 6 & 2 & 2 & 5 & 2 & & 11 & 5 & 4 \\
\hline Radioatividade Ambiental & & 7 & 6 & & 1 & 6 & 2 & 8 & 9 & 2 & 16 & 21 \\
\hline Aplicações & & 1 & & & 1 & 1 & 2 & 11 & 6 & 2 & 13 & 7 \\
\hline Equívocos & 1 & 1 & & & 1 & 3 & 2 & 1 & 2 & 3 & 3 & 5 \\
\hline Proposições confusas & & & & & & 2 & & & & 0 & 0 & 2 \\
\hline TOTAL & 11 & 19 & 16 & 16 & 25 & 24 & 26 & 40 & 40 & 53 & 84 & 80 \\
\hline
\end{tabular}

Fonte: Autores (2017).

Entre o primeiro e o segundo mapa houve um aumento de $58,5 \%$ do número de conceitos e se manteve praticamente a mesma de $\mathrm{B} \rightarrow \mathrm{C}$, conforme sugere a Tabela 1. Sinalizando terem ocorrido processos de aprendizagem subordinada, assim considerada por ser o processo pelo qual os novos conceitos ou proposições interagem com uma ideia particular pré-existente mais inclusiva de modo significativo (MOREIRA; MANSINI, 1982).

A exceção dos equívocos e proposições confusas, de $\mathrm{B} \rightarrow \mathrm{C}$ as categorias "Definição" e "Emissões Radioativas" são constantes nos três mapas dos três sujeitos e, próximo disso, a categoria "Reações Nucleares". O que significa que todos os sujeitos têm algo a dizer sobre a Radioatividade e que normalmente recorre a estes dois últimos temas. Tais indícios podem ser reflexos do contato com os livros didáticos, no tempo quando estudantes da Educação Básica (SILVA; SIMÕES NETO, 2012; TENÓRIO et al., 2015), e reforçada pela formação vivenciada no primeiro período do curso (AQUINO et al., 2016), inviabilizando ao estudante extrapolar ao traçar um paralelo entre temas como o uso da energia nuclear e os riscos eminentes de contaminação ambiental, por exemplo.

As representações quantitativas nos permitiram melhor visualizar o comportamento das principais categorias, no entanto um olhar qualitativo é necessário para complementar a análise. Para que, assim, possamos compreender como os elementos localizados modificaramse após cada licenciando ser exposto à nova informação e como esta é incorporada a sua estrutura cognitiva, o que demonstrarem a seguir e de forma individual.

\section{O caso de $\mathbf{L 1}$}

Na Figura 5, na definição de Radioatividade de L1, ao longo dos três mapas conceituais, em geral, expressa sua relação com a área da Química. Foram envolvidos conceitos com o estudo de partículas radioativas (radioisótopos) e radiações (em especial nos Mapas A e B) associadas às reações de fissão e fusão nuclear (presente no Mapa C), as quais são bastante enfatizadas no currículo de Química do Ensino Médio. 


\section{L1 - MAPA A}

\section{RADIOATIVIDADE}

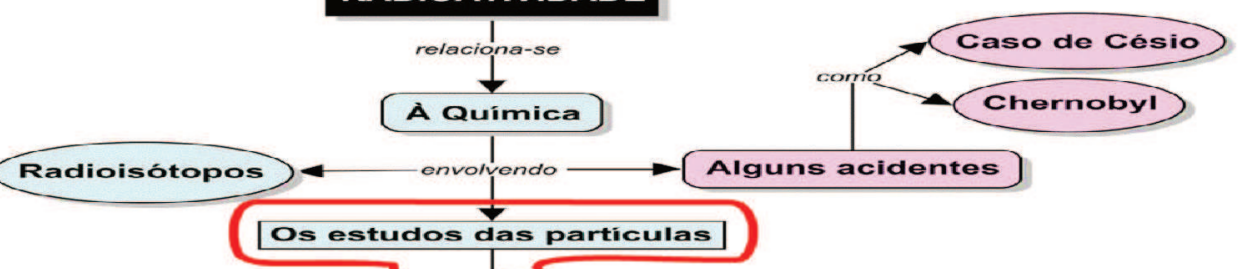

Os estudos das particulas

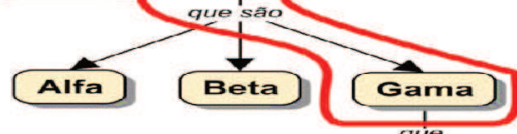

poder penetrante

\section{L1- MAPA B}

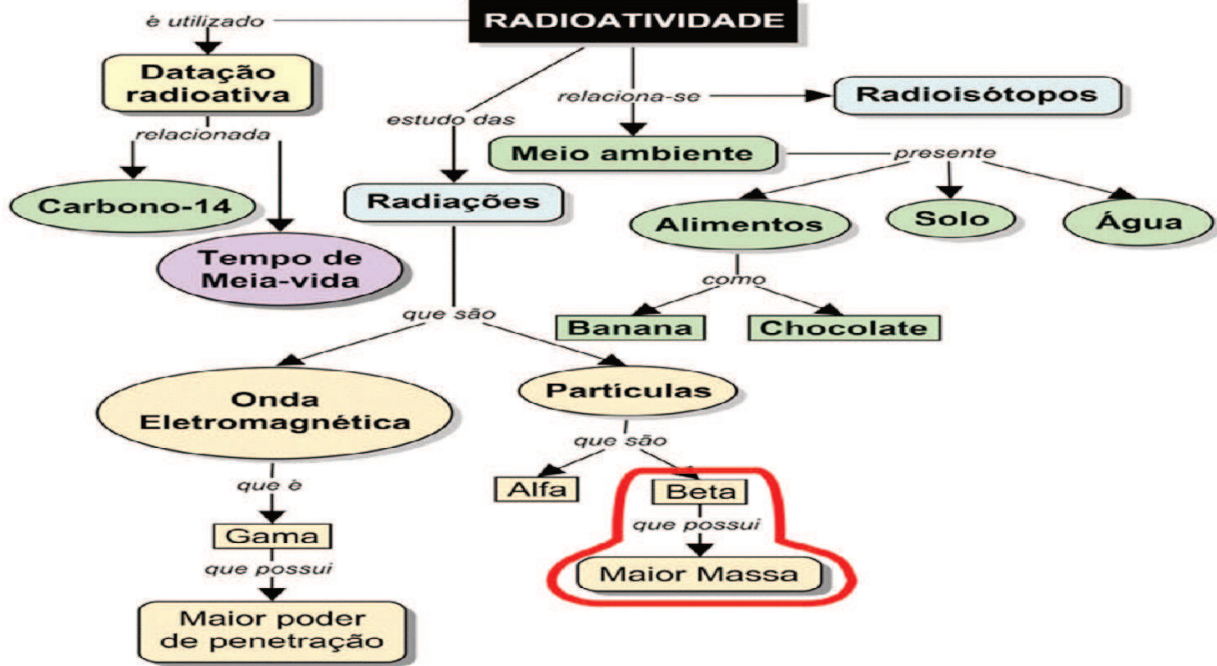

\section{L1 - MAPA C}

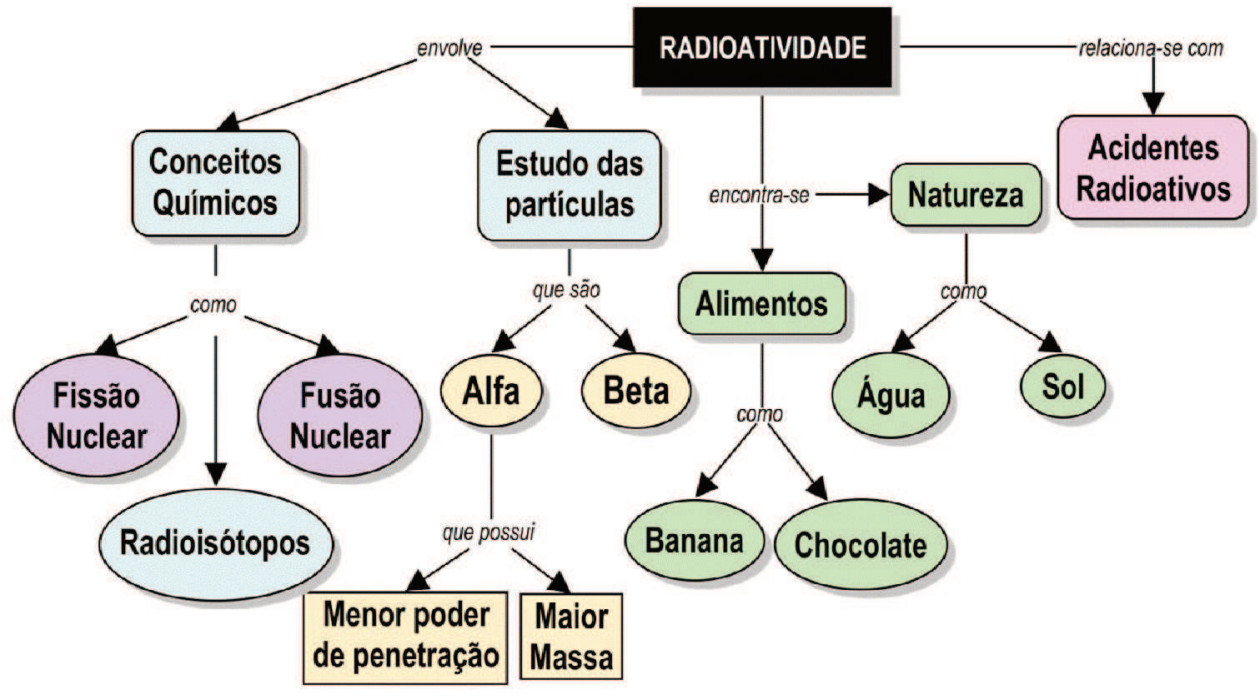

Figura 5 - Mapas conceituais de L1 reconstruídos via CmapTools.

Fonte: Autores (2017) 
Observamos que sua caracterização do fenômeno Radioatividade não destaca como principal característica a instabilidade do núcleo atômico, o qual é agente promotor de tais emissões e reações (OKUNO, 2013). Em relação às informações históricas, inicialmente L1 cita os casos de Chernobyl e o acidente com o césio-137 em Goiânia, talvez por serem estes os casos mais comuns nos livros didáticos e que trazem implicações sócio-históricas significativas (TENÓRIO et al, 2015). Porém, após o processo formativo, L1 deixa de fazer menção a elementos históricos ainda que estes tenham sido abordados antes e durante a formação, vindo a reaparecer no Mapa $\mathrm{C}$ de forma implícita e genérica, possivelmente alusivo aos casos citados no Mapa A.

No primeiro mapa, L1 não apresenta informações sobre reações nucleares e nem de casos de aplicação, vindo a ocorrer no Mapa B quando menciona a datação radiométrica e o tempo de meia-vida - conceitos lembrados apenas por este sujeito, sobretudo o conceito de meia-vida que se refere à desintegração dos núcleos radioativos de forma espontânea (RODITI, 2005). Apesar disso, no Mapa C esses elementos não foram identificados, muito provavelmente pela ação do tempo de obliteração.

Conceitos sobre emissões radioativas são gradativamente aprimorados a cada produção como indica os equívocos encontrados no Mapa A sobre a radiação eletromagnética gama como uma radiação particulada, embora acertadamente tenha afirmado ser ela a que possui o maior poder de penetração (ATKINS; JONES, 2009). L1 corrigiu sua compreensão no Mapa B sobre a natureza da radiação gama, mantendo a mesma estrutura observada anteriormente, porém descreve a radiação beta como a que possui maior massa, quando, na verdade, trata-se da radiação alfa. Posteriormente, tal descrição foi revista no Mapa C apesar de não ter mencionado nada sobre a radiação gama, mas sugerindo já existir uma clara distinção entre as emissões radioativas particuladas das de natureza eletromagnética.

Os conceitos de fissão e fusão curiosamente estão presentes apenas no Mapa C e não totalmente integrados com os demais conceitos sobre Radioatividade, mas sugerem serem conceitos significativos e relevantes. Com isso, inferimos ser necessário para este licenciando se aprofundar nessa temática, uma vez que se trata de conceitos comuns e importantes para o Ensino de Radioatividade presentes no currículo do Ensino Médio (SILVA; SIMÕES NETO, 2012). Isso porque existe a fissão espontânea decorrente da instabilidade nuclear e outra de uma colisão entre um núcleo atômico instável e um nêutron oriundo de uma fissão espontânea anterior, portanto, não radioativa e que produz um efeito cadeia de fissão por colisão. $O$ princípio é utilizado tanto no processo de geração de energia nuclear como da bomba atômica.

No início, L1 exibia informações referentes à definição, emissões radioativas e história da Radioatividade e nos mapas seguintes surgem elementos sobre aplicação e reações nucleares com certa flutuação. No entanto, os conceitos relacionados com a R.Am. 
praticamente se estabilizaram nos Mapas de $B \rightarrow C$, sugerindo que tais informações foram pertinentes para o licenciando, podendo mais tarde estabelecer conexões com os demais ramos do mapa e incorporadas à sua prática de ensino.

\section{$O$ caso de $L 2$}

Segundo apresenta a Figura 6, à medida que L2 produzia seus mapas procurava definir a Radioatividade como um processo de transformação química que ocorre no núcleo atômico (nuclídeo) e assim distingui-la das reações químicas (ATKINS; JONES, 2009).

Destacamos a definição presente no Mapa B onde apresenta uma definição mais próxima do esperado devido à ideia de estabilidade do nuclídeo, ainda que tenha cometido um equívoco ao sugerir que todo núcleo instável seja um nuclídeo. Este último é um termo utilizado para caracterizar um núcleo (radioativo ou não) com número atômico e de massa específicas (RODITI, 2005).

Apesar de L2 não exibir nenhuma informação sobre a história da Radioatividade no Mapa A, na elaboração seguinte, e acertadamente, menciona os nomes de Henri Becquerel e Marie Curie como quem, respectivamente, descobriu e desenvolveu os estudos sobre a Radioatividade (OKUNO; YOSCHIMURA, 2010). Vindo a equivocar-se nesse aspecto no Mapa C, ao atribuir todo mérito ao casal Curie, talvez por seu grande destaque nas Ciências Nuclear, tornando outros personagens dessa história secundários.

Em matéria de "Reações Nucleares", no primeiro mapa estes conceitos são destacados como informações centrais pondo em evidência a fissão e fusão, as quais culminam em processos de liberação de energia e composição de novos elementos químicos - mais comuns na fissão por necessitar de uma quantidade menor de energia para ocorrer (ROLIM, 2012). Já na segunda produção, o seu mapa se restringe a apresentar os nomes dessas reações e imediatamente citar exemplos de cada uma (aplicação: fissão $\rightarrow$ usinas; e ocorrência natural: fusão $\rightarrow$ estrelas), substituindo uma estrutura do tipo correlativa (extensão ou elaboração do conhecimento prévio) por uma estrutura derivativa (exemplo). Ao passo que no Mapa C, a respeito da fusão, a proposição "Estrelas - que produz $\rightarrow$ Elementos da Tabela Periódica", possivelmente seja indicativo referente às radiações cósmicas (OKUNO, 2013), as quais foram citadas na formação em R.Am. 
L2- MAPA A

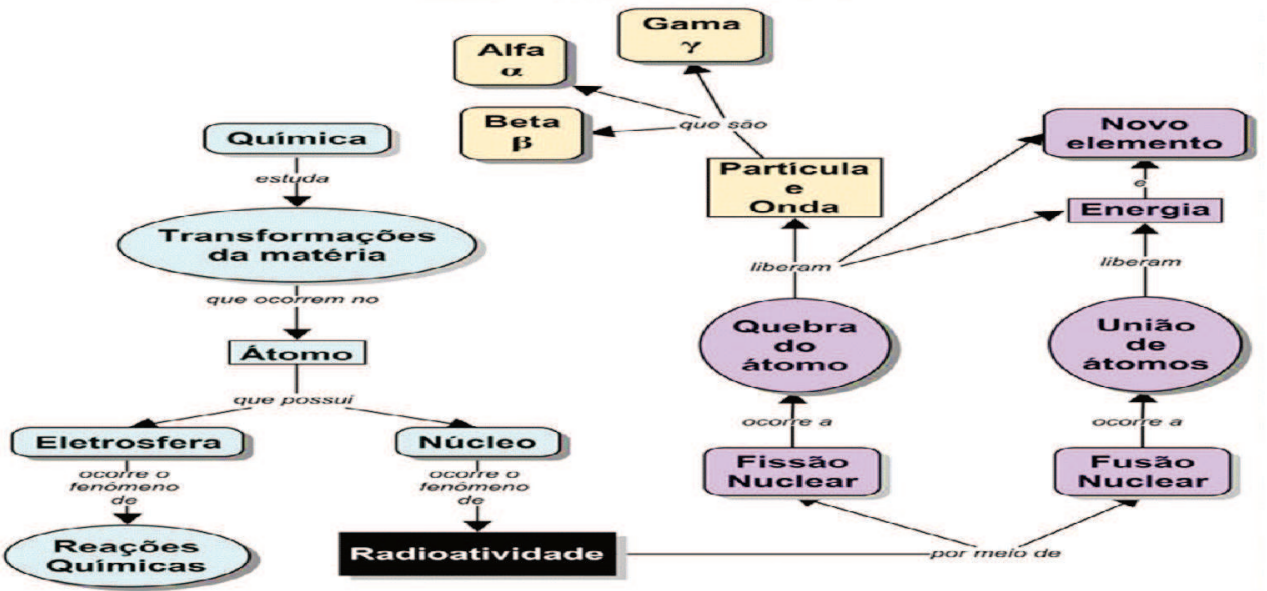

\section{L2 - MAPA B}

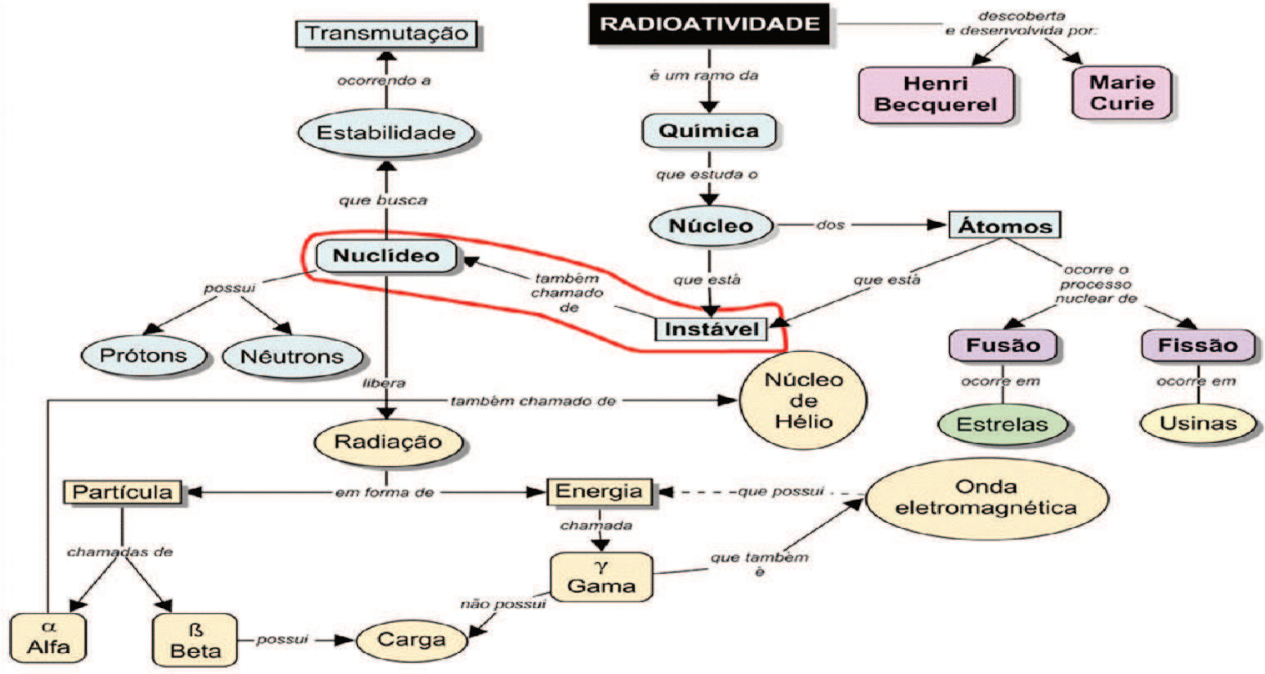

\section{L2 - MAPA C}

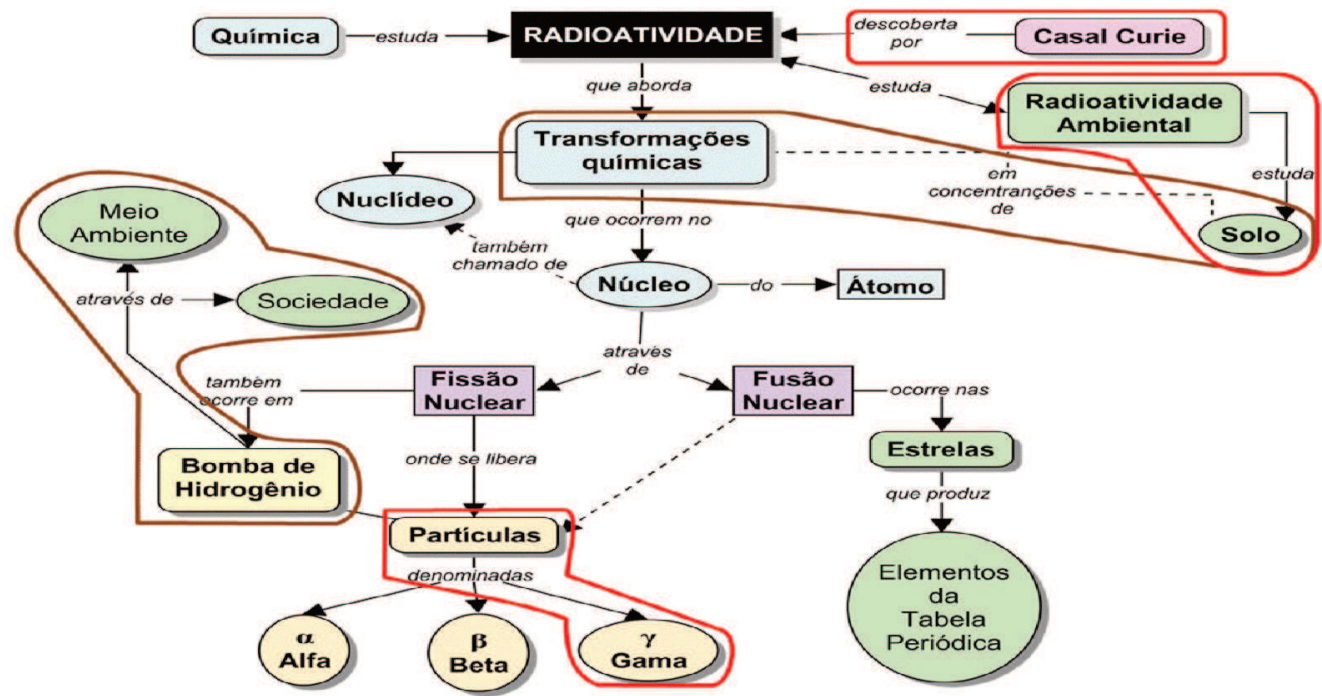

Figura 6 - Mapas conceituais de L2 reconstruídos via CmapTools.

Fonte: Autores (2017). 
Apesar da bomba de hidrogênio ser considerada uma bomba de fusão seu mecanismo de ignição se dá a partir de duas reações de fissão, teoricamente (RODITI, 2005). Entretanto, a dúvida surge quanto a real relação dessa tecnologia bélica e os conceitos de meio ambiente e sociedade, tal como também acontece com a proposição "Transformações químicas - em concentrações de $\rightarrow$ Solo" que ficaram confusos no último mapa. Disso, inferimos que podem ser referentes às repercussões e impactos socioambientais do uso da energia nuclear, e no segundo caso uma tentativa de destacar ser um processo natural.

Quanto às emissões radioativas, destacamos que inicialmente para L2 estas só ocorrem via processo de fissão nuclear, sem fazer distinção quem é do tipo corpuscular ou na forma de onda, dando indícios de uma possível dúvida ou insegurança quanto a precisa natureza das radiações alfa, beta e gama. Outra provável explicação é que durante o processo de decaimento, ao se emitir uma radiação alfa ou beta, também é emitido uma radiação gama para diminuir o estado de instabilidade do radionuclídeo (ATKINS; JONES, 2009). No Mapa $\mathrm{B}$, vemos que as radiações ocorrem na forma de energia para gama e partículas para alfa e beta. Nesse sentido, L2 reconhece que a partícula beta possui carga e a gama não. Contudo, deixa de informar a carga da partícula alfa, preferindo informar sua composição ser similar ao do núcleo de um átomo de hélio. Além disso, ao comentar sobre a natureza da radiação gama, traça uma linha de reconciliação (onda eletromagnética $\rightarrow$ energia), caracterizada mais como um mecanismo de reforço do que uma nova informação.

Embora cite mais elementos conceituais referentes à R.Am. a partir do Mapa C, estas são pouco compreensíveis ou equivocada, a exceção das que foram subordinadas ao conceito de fusão, indicando que estarem em processo de acomodação à estrutura cognitiva. De forma similar ao que L1 e L3 fizeram nos seus primeiros mapas, L2 equivoca-se ao generalizar a radiação gama como uma radiação particulada no mapa de obliteração. O que não implica dizer ser esta sua posição definitiva, pois assim como os outros equívocos e as proposições confusas detectadas suscitam a ideia de que a assimilação obliterada esteja atuando na dinâmica da reelaboração conceitual.

\section{$O$ caso de $L 3$}

Segundo a Tabela 1, L3 foi quem mais adicionou novos conceitos à sua estrutura cognitiva (cerca de 50\% do Mapa $\mathrm{A} \rightarrow \mathrm{B}$ ), mantida após um tempo, conforme ilustra a Figura 7. Em termos de "Definição", L3 busca definir a Radioatividade como um conteúdo conceitual da área de Ensino de Química. Entretanto, a partir do Mapa B são adicionados elementos que o fazem conceituar precisamente a Radioatividade como um fenômeno cujo átomo tem um núcleo instável. Mesmo no mapa de obliteração, vemos que ele continua a 
realizar uma espécie de introdução à Radioatividade, para então defini-la. No entanto, acaba se equivocando ao generalizar sua definição com o processo de reação de fissão.
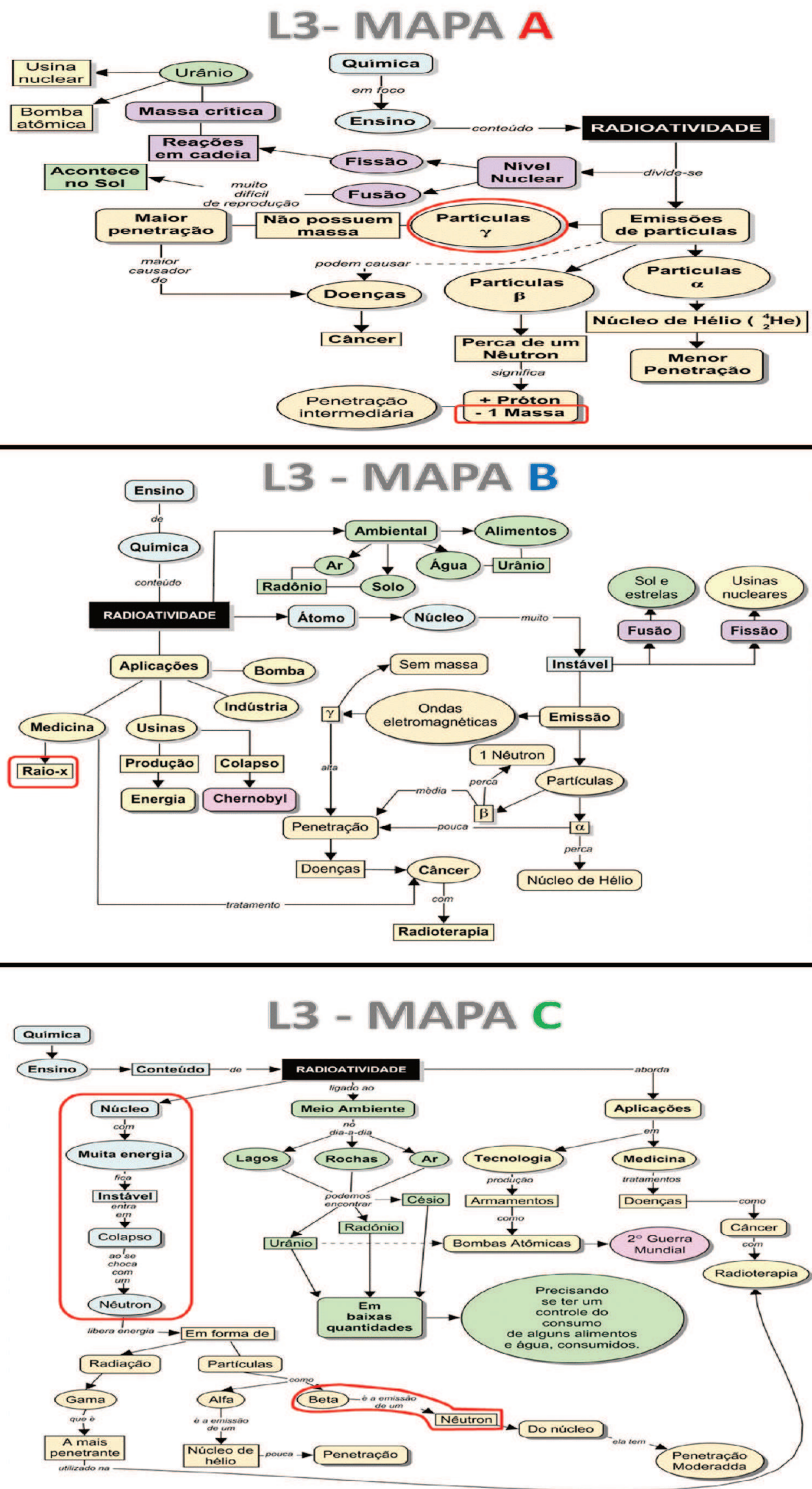

Figura 7 - Mapas conceituais de L3 reconstruídos via CmapTools.

Fonte: Autores (2017). 
No seu Mapa A não verificamos existir indícios de informações históricas, surgindo de maneira discreta no Mapa B, neste caso remetendo-se a Chernobyl. Enquanto que no Mapa C, pela primeira vez é citado o trágico episódio das bombas atômicas lançadas sobre o Japão no final da Segunda Guerra Mundial, numa estrutura derivativa das aplicações.

Isso sugere que não somente L3, mas os demais sujeitos aqui analisados, carecem de informações históricas sobre a Radioatividade, mesmo ela tendo sido desenvolvida pelo docente em aulas antes da nossa formação sobre R.Am. A partir do Mapa B, as informações sobre "Emissões Radioativas" estão diretamente associadas com a sua definiç̧ão, mas desde o início busca caracterizar quanto aos tipos, natureza, símbolo e poder de penetração. Isso fica mais evidente se observarmos que a estrutura exposta no Mapa A vai se modificando aos poucos, onde inclusive identificamos um equívoco quanto à natureza da radiação gama situação similar a de L1 no primeiro mapa.

Já em relação aos equívocos sobre a radiação beta nos Mapas A e C, notamos se tratar da mesma questão: o processo da radiação beta. Isto porque menciona que na radiação beta há a perda de um nêutron e, com isso, de massa atômica, quando na verdade esta é decorrente das transformações de um nêutron instável, cujos produtos são um próton (que permanece no núcleo), uma partícula beta e um antineutrino $(v)$ conforme equação: ${ }_{0} n^{1} \rightarrow{ }_{1} p^{1}+{ }_{-1} \beta^{0}+{ }_{0} v^{0}$ (KAPLAN, 1963).

Apesar do tema das "Reações Nucleares" seja melhor desenvolvido no Mapa A, essas informações foram desaparecendo a ponto de não serem mais encontradas no mapa de obliteração de L3, a exceção dos indícios sobre fissão nuclear presentes na definição. Como também observado em L1, trata-se de um acontecimento preocupante à medida que envolve fenômenos importantes não só para o desenvolvimento de novas tecnologias, mas que envolve a formação de novos elementos químicos e mesmo da composição da radiação cósmica (tal como observamos em L2), além do conceito de decaimento radioativo que não foi mencionado por nenhum dos sujeitos analisados.

Nota-se que os exemplos citados no Mapa A, também estão no segundo, no entanto, dentro de um ramo mais estruturado e com novas informações, equivocando-se apenas quanto ao Raio-X, uma radiação proveniente da eletrosfera. Já no Mapa C, uma nova informação foi à palavra radioterapia, que é uma aplicação médica. E mesmo diante da redução de conceitos voltados para a categoria "Aplicação" no Mapa C, é mantida a relação Medicina e tratamento do câncer, exclusivamente citado por L3 ao longo da pesquisa.

Em termos de "Radioatividade Ambiental", L3 contemplou praticamente todas as informações mencionadas na formação nos dois primeiros mapas, faltando-lhe articular com os radionuclídeos artificiais. Ao passo que no Mapa $\mathrm{C}$ as informações sobre R.Am. se encontram amparadas numa nova estrutura de subordinação completamente independente tal 
como observamos no Mapa C de L1, porém mencionando novos elementos com o Césio e Radônio, ressaltando a presenta deles em alimentos e na água.

Dessas inferências percebemos que informações quanto à Radioatividade Natural ela é, sim, abordada de modo superficial, no entanto, o Ensino de Radioatividade tende a enfatizar os tipos de emissões, cálculos de reações, alguns elementos históricos e aplicações tecnológicas (SILVA; SIMÕES NETO, 2012). Omitindo informações que possam levar o estudante a relacionar que os elementos radioativos são encontrados na natureza e, por isso, interagem com o homem por meio dos diferentes compartimentos do ecossistema (MAZZILLI et al., 2011).

E independentemente de não termos detectado proposições confusas nos mapas pré e pós-formação, muitos trechos dos mapas conceituais de L3 não apresentavam os conectivos. Segundo comenta Tavares (2007), um mapa para ser considerado conceitual, dentro da perspectiva da Aprendizagem Significativa, necessita ser hierárquico e composto por conceitos interligados por linhas que apresentam um conectivo que explicita a relação entre os conceitos.

Mesmo tendo sido explicado aos licenciandos como se proceder na elaboração de um mapa conceitual, tanto pelo docente como pelos pesquisadores durante a formação, observamos que os sujeitos participantes adotaram um estilo próprio no momento da confecção dos mapas conceituais, o que inclui o não uso de conectivos. O que particularmente dificulta identificar o sentido das relações entre os conceitos subordinados; mas não inviabilizar a sua análise por se tratar de uma produção pessoal.

Desta forma, os mapas de obliteração indicam que os sujeitos analisados tendem à conservar certas correlações em suas estruturas cognitivas, como nitidamente observada em L1, mesmo tendo incorporado novos elementos quanto à Radioatividade Ambiental. Que aos poucos tem provocado reconciliações, presentes em L2, para se consolidar como uma nova raiz na estrutura cognitiva tal como se encontrado em L3.

Apesar dos licenciandos terem alguma noção do uso das emissões radioativas, estas ainda são restritas e fracamente dialogam sobre os impactos sociais da Radioatividade (COSTA et al., 2016), sugerindo que os mesmos se aprofundem no tema (MESSEDER et al., 2013).

\section{Considerações finais}

Tendo em vista as limitações presentes no Ensino de Radioatividade como a impossibilidade de manuseio de compostos radioativos em sala de aula, vislumbramos ser possível contextualizar tal conteúdo através da perspectiva ambiental por ser a Radioatividade um fenômeno natural. Isto porque ao se ensinar o conteúdo conceitual sobre Radioatividade 
há uma tendência em mencionar a manipulação de elementos como urânio e rádio, quando na verdade existe uma variedade de elementos radioativos com os quais constantemente interagimos através dos alimentos, do ar que respiramos e dos lugares por onde circulamos.

Essa perspectiva ambiental busca contribuir de modo significativo para a contextualização do Ensino de Radioatividade, em virtude de seu caráter inovador. E isso pode ser constatado nos mapas conceituais dos licenciandos aqui analisados, instigando-os a estabelecer relações seja com os elementos naturais (L1), com os temas sociais (L2) ou aplicações tecnológicas (L3). O que contribui para o desenvolvimento de uma prática de ensino menos abstrata e que ganha maiores dimensões quando o licenciandos dispõe de claras informações sobre este fenômeno ainda no curso de formação inicial.

\section{Referências}

AQUINO, K. A. S.; SILVA, R. M.; TENÓRIO, A. C. O ensino de radioatividade nos cursos de formação de professores de química no estado de Pernambuco. In: CONGRESSO INTERNACIONAL DE TECNOLOGIA NA EDUCAÇÃO, 14., 2016, Recife. Anais eletrônico... Recife, 2016. Disponível em: <https://slidex.tips/download/o-ensino-deradioatividade-nos-cursos-de-formaao-de-professores-de-quimica-no-es $>$. Último acesso em: 22 nov. 2018.

AQUINO, K. A. S; AQUINO, F. da S. Radioatividade e meio ambiente: os átomos instáveis da natureza. São Paulo: Sociedade Brasileira de Química, 2012.

AQUINO, K. A. S.; CHIARO, S. de. Uso de mapas conceituais: percepções sobre a construção de conhecimentos de estudantes do ensino médio a respeito do tema radioatividade. Ciências \& Cognição, v. 18, n. 2, p. 158-171, 2013.

ATKINS, P. W.; JONES, L. Princípios de química: questionando a vida moderna e o meio ambiente. 5. ed. Porto Alegre: Bookman Editora, 2009.

AUSUBEL, D. P. Aquisição e retenção de conhecimentos: uma perspectiva cognitiva. Lisboa: Plátano Edições Técnicas, 2000.

AUSUBEL, D. P.; NOVAK, J. D.; HANESIAN, H. Psicologia educacional. Rio de Janeiro: Interamericana, 1980.

BARDIN, L. Análise de conteúdo. Lisboa: Edições 70, 1994.

BONOTO, D. M. Radioatividade nas águas: da Inglaterra ao Guarani. São Paulo: Editora UNESP, 2004.

BRASIL. Parâmetros Curriculares Nacionais para o Ensino Médio. Ministério da Educação. Secretaria de Educação Média e Tecnológica. Brasília: MEC/SEMTEC, 2000. 
BRASIL. Orientações curriculares nacionais para o ensino médio: ciências da natureza, matemática e suas tecnologias. Ministério da Educação Básica. Secretária de Educação Básica. Brasília: MEC/SEB, 2006. v. 2.

CHIZZOTTI, A. A pesquisa qualitativa em ciências humanas e sociais: evolução e desafios. Revista Portuguesa de Educação, v. 16, n. 2, p. 221-236, 2003.

COSTA, R. C.; PINHEIRO, B. C. S.; MORADILLO, E. F. A radioatividade nos livros didáticos do PNLD 2015: uma análise crítica no PIBID/Química. In: ENCONTRO NACIONAL DE ENSINO DE QUÍMICA, 18., 2016, Florianópolis. Anais eletrônicos... Florianópolis, 2016. Disponível em: <http://www.eneq2016.ufsc.br/anais/resumos/R16941.pdf>. Último acesso em: 23 jun. 2018.

DOMINGUINI, F.; CLEMES, G.; ALLAIN, O. Análise do tema radioatividade nos livros didáticos no PNLDEM à luz da teoria da aprendizagem significativa e dos pressupostos $\mathrm{C}$, T\&S. Revista Técnico Científica (IFSC), v. 3, n. 1, p. 455-466, 2012.

FERREIRA, A. O. Avaliação da radioatividade natural em algumas rochas graníticas do estado do Paraná e sua utilização na construção civil. Tese de doutorado em Ciências Instituto de Pesquisas Energéticas e Nucleares, São Paulo, 2013.

FRANCO, M. A. S. Pedagogia da pesquisa-ação. Revista Educação e Pesquisa, São Paulo, v. 32, n. 3, p. 483-502, 2005.

HENEINE, I.F. Biofísica básica. 2. reimpr. Rio de Janeiro: Atheneu Editora, 1991.

JACOB, L. F. R.; MESSEDER, J. C. Radioatividade a partir de vídeos educativos: propostas para aulas de química. In: ENCONTRO NACIONAL ENSINO DE QUÍMICA, 16., Salvador. Anais eletrônicos... Salvador, 2012. Disponível em: $<$ https://portalseer.ufba.br/index.php/anaiseneq2012/article/viewFile/7821/5546>. Último acesso em: 23 jun. 2017.

JESUS, M. A. S.; SILVA, R. C. O. A teoria de David Ausubel - o uso dos organizadores prévios no ensino contextualizado de funções. In: ENCONTRO NACIONAL DE EDUCAÇÃO MATEMÁTICA, 8., 2004, Recife. Anais eletrônicos... Recife, 2004. Disponível em: <http://www.sbem.com.br/files/viii/pdf/03/MC05002402801.pdf>. Último acesso em: 23 jun. 2018.

KAPLAN, I. Nuclear Physics. New York: Addison-Wesley Publishing Comp., Inc., 1963.

LIBÂNEO, J. C. Didática. 2. ed. 1. reimpr. São Paulo: Cortez, 2013.

LUCKESI, C. C. Filosofia da educação. São Paulo: Cortez, 1994. (Coleção Magistério $2^{\circ}$ grau. Série Formação do Professor).

MAZZILLI, B. P.; MÁDUAR, M. F.; CAMPOS, M. P. Radioatividade no meio ambiente e avaliação de impacto radiológico ambiental. São Paulo: IPEN, 2011.

MESSEDER, J. C.; PIRES, T. C. A.; PIRES, R. de O. Materiais midiáticos e temas sociais: ampliando a prática do ensino CTS na licenciatura em química. In: ENCONTRO NACIONAL DE PESQUISA EM EDUCAÇÃO EM CIÊNCIAS, 9., 2013, Águas de Lindoia. Atas eletrônicos... São Paulo, 2013. Disponível em: 
$<$ http://www.nutes.ufrj.br/abrapec/ixenpec/atas/resumos/R0026-1.pdf>. Último acesso em: 23 jun. 2017.

MOREIRA; M. A.; MANSINI, E. F. S. Aprendizagem significativa: a teoria de David Ausubel. São Paulo: Editora Moraes, 1982.

MOREIRA, M. A.; VALADARES, J. A.; CABALLERO, C.; TEODORO, V.D. Teoria da Aprendizagem significativa: contributos do III Encontro Internacional sobre aprendizagem significativa-Peniche-2000.

Disponível em: <http://www.mlrg.org/memberpublications/LivroPeniche2000.pdf>. Último acesso em: 22 nov. 2018.

MOREIRA, C. H. P. M. A contextualização no âmbito da prática como componente curricular de genética. Dissertação de mestrado em Ensino das Ciências e Matemática Universidade Federal Rural de Pernambuco, Recife, 2017.

NOVAK, J. D.; GOWIN, D. B. Aprendiendo a aprender. Barcelona: Editora Martínez Roca, 1988.

OKUNO, E. Efeitos biológicos das radiações ionizantes. Acidente radiológico de Goiânia. Estudos Avançados, São Paulo, v. 27, n. 77, p. 185-199, 2013.

OKUNO, E.; YOSHIMURA, E. M. Física das radiações. São Paulo: Oficina de Textos, 2010.

OLIVEIRA, M. M. Como fazer pesquisa qualitativa. Recife: Bagaço, 2005.

RODITI, I. Dicionário Houaiss de Física. Rio de Janeiro: Editora Objetiva, 2005.

ROLIM, T. T. L. Brasil e Estados Unidos no contexto da "Guerra Fria" e seus subprodutos: Era Atômica e dos Mísseis, Corrida Armamentista e Espacial, 1945-1960. Tese de doutorado em História - Universidade Federal Fluminense, Niterói, 2012.

SÁ, M. B. Z.; SANTIN FILHO, O. Relação entre ciência, tecnologia e sociedade em livros didáticos de química. Acta Scientiarum. Human and Social Sciences, v. 31, n. 2, p. 159-166, 2009.

SANTOS, S. M. O.; MÓL, G. S. Critérios para a avaliação de livros didáticos de química para o ensino médio. In: ENCONTRO NACIONAL DE PESQUISA EM EDUCAÇÃO EM CIÊNCIAS, 5., Bauru. Anais...Bauru, 2006. 1 CD-ROM.

SILVA, F. C. V.; SIMÕES NETO, J. E. A radioatividade nos livros didáticos do ensino médio - um olhar utilizando elementos da transposição didática. In: ENCONTRO NACIONAL ENSINO DE QUÍMICA, 16., Salvador. Anais eletrônicos... Salvador, 2012. Disponível $\mathrm{em}$ : <https://portalseer.ufba.br/index.php/anaiseneq2012/article/viewFile/7327/5107>. Último acesso em: 23 jun. 2018.

SILVA, R. M. da. A radioatividade ambiental na formação inicial de professores de química na perspectiva da aprendizagem significativa. Dissertação de mestrado em Ensino de Ciências - Universidade Federal Rural de Pernambuco, Recife, 2017. 
SILVA, R. M.; CESAR, H. P. M.; GARCIA, C. C. V.; AQUINO, K. A. S.; SILVA, S. A. Análise de conteúdo em mapas conceituais sobre radioatividade. In: CONGRESSO INTERNACIONAL DE TECNOLOGIA NA EDUCAÇÃO, 15., 2017, Recife. Anais eletrônico... Recife, $2017 . \quad$ Disponível em: $<$ http://demo.cubo9.com.br/senac/pdf/comunicacao-oral/008.pdf>. Último acesso em: 23 jun. 2018.

TAVARES, R. Construindo mapas conceituais. Ciência \& Cognição, v. 12, n. 8, p. 72-85, 2007.

TENÓRIO, A. QUINTANA, L. S.; NUNES, W. V.; TENÓRIO, T. Análise de conteúdo de física nuclear em livros escolares brasileiros. Revista Electrónica de Enseñanza de las Ciencias, v. 14, n. 2, p. 175-199, 2015.

THIOLLENT, M. Metodologia da pesquisa-ação. 14. ed. São Paulo: Editora Cortez, 2005.

VALÉRIO, M. Mapas para ensinar e aprender conceitos de ciências: caçando o tesouro da aprendizagem significativa. In: DUSO, L.; HOFFMANN, M. B. (Orgs.). Docência em ciências biológicas: propostas pra um continuado (re)iniciar. Ijúi: Editora Unijuí, 2013, p. 229-252.

VASCONCELOS, D. C. Estudo da radioatividade natural em areais de praias do extremo sul da Bahia utilizando métodos de análises nucleares. Tese de doutorado em Ciências e Técnicas Nucleares - Universidade Federal de Minas Gerais, Belo Horizonte, 2010.

\section{SOBRE AS AUTORAS}

ROBERTA MARIA DA SILVA. Mestre pelo Programa de Pós-graduação em Ensino das Ciências (PPGEC) da Universidade Federal Rural de Pernambuco (UFRPE) em 2017. Graduada em Licenciatura Plena em Química pela UFRPE (2013). Técnica em Agropecuária pelo Colégio Dom Agostinho Ikas (CODAI/UFRPE) em 2007. Atualmente é professora do Pré-vestibular da Universidade de Pernambuco (PREVUPE) desde 2013; do Colégio e Curso Opção e da Escola de Referência de Ensino Médio Professor Moacyr de Albuquerque.

https://orcid.org/0000-0003-2417-4518

KÁTIA APARECIDA DA SILVA AQUINO. Possui pós-doutorado em Educação Tecnológica pelo programa de Pós Graduação em Educação Matemática e Tecnológica (EDUMATEC) da Universidade Federal de Pernambuco (2014). Possui Doutorado (2005) e Mestrado (2000) em Tecnologias Energéticas e Nucleares pela Universidade Federal de Pernambuco e é graduada em Licenciatura Plena em Química pela Universidade Federal Rural de Pernambuco (1995). É professora Titular do Colégio de Aplicação/Centro de Educação, membro do Programa de Pós Graduação em Tecnologias Energéticas e Nucleares (PROTEN-DEN-CRCN/NE) e do Programa de Mestrado Profissional em Rede Nacional de Ensino das Ciências Ambientais para Professores de Ensino Básico (PROF-CIAMB), ambas as atividades realizadas na Universidade Federal de Pernambuco. É líder do Grupo de Estudos e Pesquisa sobre Aprendizagem Significativa (GEPAS), no Colégio de Aplicação da UFPE, atuando em pesquisas sobre práticas de inovação e experimentação didático-pedagógicas e formação docente à luz da Teoria da Aprendizagem Significativa.

https://orcid.org/0000-0001-8895-6637

SUELY ALVES DA SILVA. Graduada em Licenciatura Plena em Química pela Universidade Federal Rural de Pernambuco (1994), mestrado em Química pela Universidade Federal da Paraíba (1998) e Doutorado em Química pela Universidade Federal da Paraíba 
(2002). Pós-Doutorado em Educação pela UFRN (2013). Professora Associado nível IV da Universidade Federal Rural de Pernambuco, com experiência na área de Educação, ênfase em Ensino-Aprendizagem e Formação de Professores, atuando principalmente nas seguintes linhas de pesquisa: Ensino de química, Educação, Formação Inicial e Continuada de Professores. Coordenadora do Curso de Especialização em Formação de Educadores da UFRPE/Departamento de Educação. Professora do Mestrado e Doutorado do Programa de Pós-Graduação no Ensino das Ciências / UFRPE- Departamento de Educação. Professora do Curso de Licenciatura Plena em Química e Licenciatura em Pedagogia/UFRPE. https://orcid.org/0000-0001-6373-6929.

Recebido: 30 de outubro de 2017.

Revisado: 31 de julho de 2018.

Aceito: 11 de outubro de 2018. 